Document downloaded from:

http://hdl.handle.net/10251/83425

This paper must be cited as:

Payri Marín, R.; Viera Sotillo, JP. (2016). The effect of nozzle geometry over internal flow and spray formation for three different fuels. Fuel. 183:20-33. doi:10.1016/j.fuel.2016.06.041.

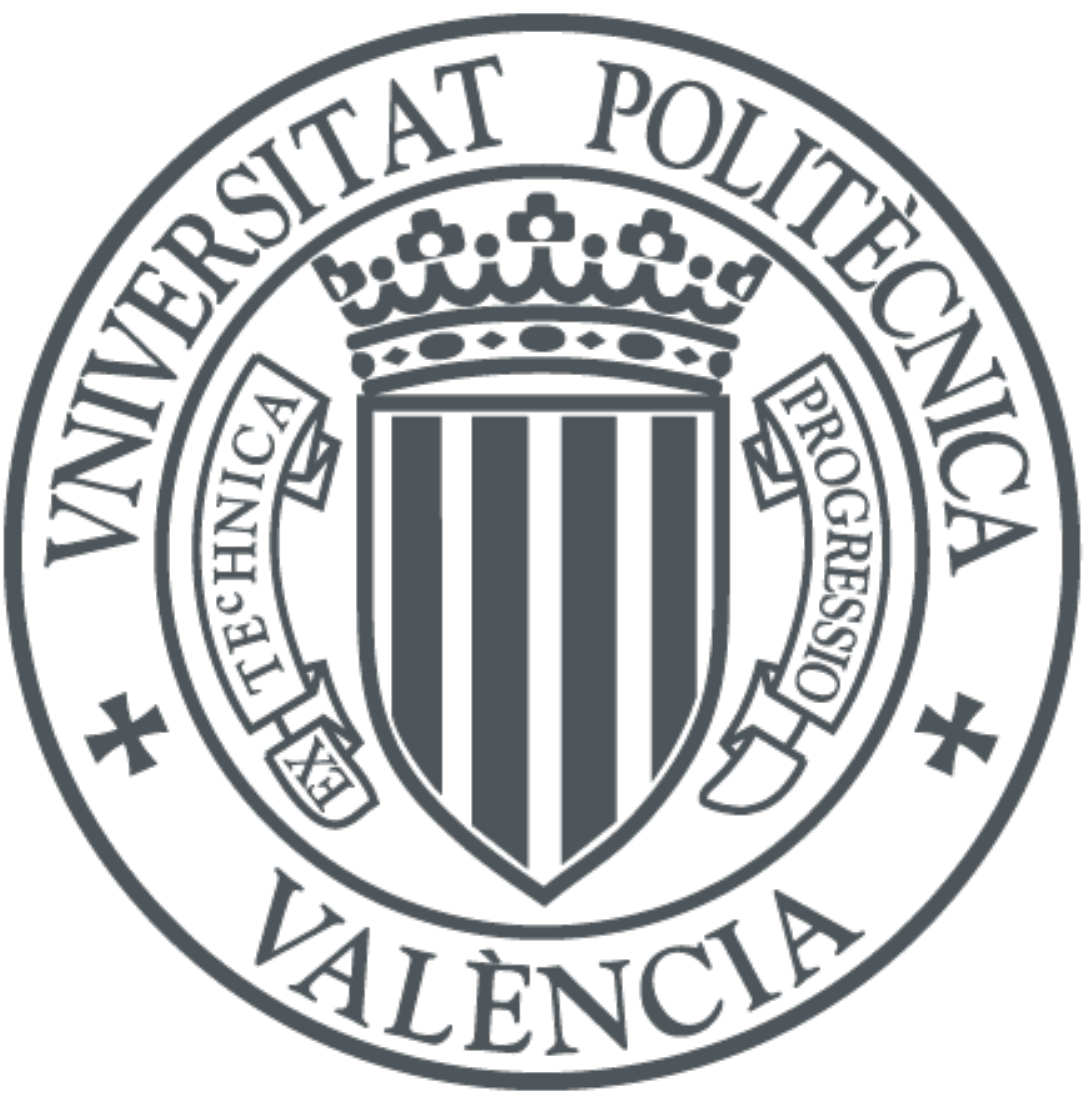

The final publication is available at

http://doi.org/10.1016/j.fuel.2016.06.041

Copyright Elsevier

Additional Information 


\title{
The effect of nozzle geometry over internal flow and spray formation for three different fuels
}

\author{
Raul Payri ${ }^{\mathrm{a}, *}$, Juan P. Viera ${ }^{\mathrm{a}}$, Venkatesh Gopalakrishnan ${ }^{\mathrm{b}}$, Patrick G. \\ Szymkowicz ${ }^{\mathrm{b}}$ \\ ${ }^{a}$ CMT-Motores Térmicos, Universitat Politècnica de Valencia, Camino de Vera s/n, \\ 46022 Valencia, Spain \\ ${ }^{b}$ Diesel Engine Systems Group, Propulsion Systems Research Lab, GM R\&D Center, \\ MC: 480-106-252, 30500 Mound Rd., Warren, MI 48090-905, USA
}

\begin{abstract}
1 The influence of internal nozzle flow characteristics over macroscopic spray development is studied experimentally for two different nozzle geometries and three fuels. The measurements include a complete hydraulic characterization consisting of instantaneous injection rate and spray momentum flux measurements, followed by a high-speed visualization of isothermal liquid spray in combination with cylindrical and conical nozzle configurations. Two of the fuels are pure components - n-heptane and n-dodecane-while the third fuel consists of a three-component surrogate to better represent the physical and chemical properties of diesel fuel. The cylindrical nozzle with $8.6 \%$ larger diameter, in spite of higher mass flow rate and momentum flux, shows slower spray tip penetration when compared to the conical nozzle. The spreading angle is found to be inversely proportional to the spray tip penetration. The spreading angle is largely influenced by the nozzle geometry and the ambient density. Rail pressure was found to have weak influence on the near-field spreading angle and no influence on the standard deviation of the spreading angle. n-Heptane spray shows slowest penetration rates while n-dodecane and the surrogate fuel mixture show very similar spray behavior

\footnotetext{
*Corresponding author

Email address: rpayri@mot.upv.es (Raul Payri)

${ }^{1}$ Raul Payri, Juan P. Viera, Venkatesh Gopalakrishnan, Patrick G. Szymkowicz,
} The effect of nozzle geometry over internal flow and spray formation for three different fuels, Fuel, Volume 183, 1 November 2016, Pages 20-33, ISSN 0016-2361, http://dx.doi.org/10.1016/j.fuel.2016.06.041.
\end{abstract}


for variations in injection pressure and back pressure. However, the surrogate fuel mixture shows higher penetration than n-dodecane when using the conical nozzle and lower penetration than n-dodecane when using cylindrical nozzle.

Keywords: Nozzle flow characteristics, macroscopic spray development, surrogate fuels, isothermal spray vizualization

\section{Introduction}

Discovered over a century ago, internal combustion engines have shaped and defined the world known today. Engine performance, fuel economy, and pollutant control have improved dramatically over the last three decades. Nevertheless, there is still interest in further development that warrants a critical and detailed evaluation of the combustion process largely influenced by fuel-air mixing $[1,2]$. To this end, computational fluid dynamic (CFD) models offer unmatched advantages over experimental approaches due to the large amount of temporal and spatial information they are able to provide. The predictive capability of validated CFD models can cut final product costs dramatically. However, current state of the art models are not completely predictive and hence, high-fidelity experimental data is still necessary to validate these models and provide accurate initial and boundary conditions to the simulations.

Majority of current spray models employ initial and boundary conditions at the nozzle exit as an indirect coupling to the flow inside the nozzle $[3,4,5,6]$. Such methods often dampen or lead to loss of smaller scale nozzle flow characteristics. Hence, the computed spray development using the indirect coupling is mainly dictated by momentum, aerodynamics, and mixing. In support of such methods, Badock et al. [7] and later Ganippa et al. [8] presented results claiming that nozzle flow characteristics have negligible influence over the spray formation and that momentum is the only controlling variable for mixing. Contrasting these studies, several authors show that the flow inside the nozzle influences the near-nozzle region of the spray in terms of liquid-phase break-up, liquid length, and spray angle $[9,10,11,12,13,14,15,16]$. Many other studies also evidence the effects of nozzle flow characteristics over the macroscopic spray $[17,11,18,3,19,4,6,20]$. This contrast, along with the remaining uncertainty on the effect of nozzle geometry on entrainment, combustion, and 
pollutant formation, leave room for fundamental questions on the subject.

Fundamental questions demand detailed information on physical phenomena that are difficult to observe experimentally. This information can be obtained from a properly validated computational spray model that directly couples the nozzle to the spray volume. A few authors have published computational models that employ a full grid comprising the nozzle internal geometry and the spray $[21,22,23,24,25,26]$. It is important to point out that the work presented by Desantes et al. [21, 26] and Xue et al. [24, 25] have benefited significantly by the considerable size and quality of the Engine Combustion Network (ECN) open database and efforts (http://www.sandia.gov/ecn/, [27]), which allowed access to very high resolution tomographies of the internal nozzle geometry, along with extensive experimental data from different institutions around the world. However, the effects of nozzle geometries on spray formation, and to some extent, fuel properties, were still out of the scope of these studies and so these publications do not answer the questions raised about the effects of nozzle flow and fuel characteristics over the macroscopic spray.

In order to achieve fully predictive CFD models, it is essential to eliminate the uncertainty in physical and chemical properties. The development of surrogate fuels is one way to achieve this while providing detailed chemical kinetic mechanisms $[28,29,30]$ further reduced to computable sizes [29, 31] that can be employed in a fully reactive spray model. Surrogate fuels are often carefully tailored to mimic the behavior of real diesel fuel over the particular diagnostic being performed [29, 32, 33].

For some years, the surrogate of choice for diesel fuel has been a singlecomponent species n-heptane. There have been more than a hundred studies of diesel combustion that have used n-heptane as a convenient surrogate. There have been two important reasons for this choice. First, n-heptane has a Cetane number of 56 that is reasonably close to the Cetane number of common diesel fuel, so its ignition is similar to that of diesel fuel which is convenient for ignition or heat release studies [34, 28, 4, 31, 35]. In addition, a detailed kinetic reaction mechanism for n-heptane was published by Curran et al. [28] in 1998 with all of the detail required to carry out thorough combustion studies. Recently, it has become apparent that n-heptane is not sufficient as a diesel surrogate, for instance, Idicheria and Pickett [36] showed that the n-heptane flame produces considerably less soot than a \#2 diesel flame at similar conditions, and the soot distribution within the flame was also found to be quite different. Therefore, richer surrogates containing aro- 
matics and other species that are important components in diesel fuels must also be represented in the surrogate selected for this study.

Although combustion performance is out of the scope of this publication, different fuels will present different behaviors regarding nozzle flow characteristics. Som et al. [37] presented a study of the effects of fuel properties on cavitation characteristics and nozzle-outlet turbulence kinetic energy. However, the study does not show the influences that different cavitation regimes found for each fuel may have on spray formation. Chen et al. [38] presented a study analyzing the effects of diesel and four alternate fuels on droplet diameters, spray penetration and cone angle. However, the effects of cavitation and nozzle flow characteristics are not contrasted with fuels in the paper. On this context, although the link between nozzle flow characteristics and macroscopic spray formation has been partially studied - especially linking the effects of nozzle geometry and cavitation to the spray formation-little to no information is found in the literature regarding the effects of fuel properties on nozzle flow and the corresponding macroscopic spray development, especially combining these with cavitating regimes [39].

This study is a contribution to the current understanding of the effects of nozzle flow characteristics over the macroscopic spray development. All experiments were performed for two different nozzle geometries and three fuels. The experimental campaign consisted in a complete hydraulic characterizationinstantaneous injection rate and spray momentum flux measurements - followed by a high-speed visualization of the isothermal liquid spray. With these experiments, two main goals are pursued: first, to evaluate the influence of nozzle flow characteristics over the macroscopic spray with supporting experimental data and second, an effort is made in obtaining and reporting high-quality experimental data in order to gather a large database useful for CFD model validations with different fuels. Therefore, state of the art experimental techniques are applied at each particular diagnostic performed in order to guarantee the quality of data reported.

\section{Materials and methods}

\subsection{Hardware}

\subsubsection{The fuel injection system}

A common-rail injection system consisting of a high pressure pump and a conventional rail with an electronic pressure regulator is used. This system can generate relatively high rail pressures of up to $220 \mathrm{MPa}$ and maintain 
it at the set value while injecting fuel. The injector body temperature was maintained close to $343 \mathrm{~K}$ using a special injector holder designed to have coolant flowing at a controlled temperature in direct contact with the injector body [40], as depicted in Figure 1. This temperature is used to estimate viscosity and density of fuel inside the nozzle. The injector's return line was pressurized to $0.6 \mathrm{MPa}$ as required by the injectors to work properly. The entire fuel injection system is electronically controlled and all the settings are introduced digitally.

\subsubsection{Nozzles}

All experiments were performed for two different nozzles, mounted on two independent injector bodies. Table 1 summarizes the injectors utilized and their nominal nozzle geometries. The injectors are piezo-electric actuaded injectors. The two nozzles are micro-sac type single-hole nozzles, with different conicity but equal hydro grinding (13.5\% each) and nominal flow rate $\left(124 \mathrm{~cm}^{3} / \mathrm{min} / 10 \mathrm{MPa}\right.$ each). Note that Table 1 includes reference symbol and color columns which indicates the symbols and/or colors that will be used to distinguish nozzles in the results section.

Table 1: Injector hardware utilized and nominal nozzle geometries.

\begin{tabular}{cccccc}
\hline Nozzle ref. & Nozz. type & Do $[\mu m]$ & k-factor & Ref. symbol & Ref. color \\
\hline k0 & micro-sac & 151 & 0 & $\diamond$ & purple \\
k15 & micro-sac & 138 & 1.5 & $\circ$ & green \\
\hline
\end{tabular}

\subsubsection{Fuels}

All experiments were also performed for three different fuels. The first fuel selected is n-heptane. As stated in the Introduction section, n-heptane has long been utilized as a diesel surrogate to mimic diesel fuels in ignition and/or heat release studies [34, 28, 4, 31]. The second fuel selected is n-dodecane, which features similar carbon content and boiling characteristics to those of diesel fuels, so it is expected to better mimic the mixing behavior of diesel fuels. This is one of the reasons n-dodecane was also selected as the primary fuel of study for the main ECN campaign [27], and it has been extensively characterized in the complete spectrum of experimental diagnostics and numerical simulations performed by the group. However, n-dodecane is not expected to be an adequate surrogate for ignition-related behavior, because 
of its Cetane number (approx. 88). Last, a multi-component diesel surrogate consisting of n-tetradecane (0.5), n-decane (0.25) and $\alpha$-methylnaphthalene (0.25) is utilized. Numbers in parentheses represent mass fractions. This surrogate - from this point forward simply referred to as "Surrogate" - is expected to better mimic the soot-related behavior of real diesel fuel due to the $\mathrm{PAH}$ content and $\mathrm{C} / \mathrm{H}$ ratio being closer to that of real diesel fuel. The short ignition delays expected due to the large n-tetradecane and n-decane contents (with Cetane numbers close to 96 and 77 respectively) are, at the same time, delayed by the the $\alpha$-methylnaphthalene content. Nevertheless, combustion behavior is out of the scope of this publication, so only the fuel properties relevant to this study are summarized in Table 2.

Table 2: Fuels utilized and their properties at $298 \mathrm{~K}$ and $101 \mathrm{kPa}$. Except for the Surrogate fuel, all properties were extracted from the NIST Chemistry WebBook [41]. For the Surrogate fuel, density, viscosity and surface tension were measured as per ASTM D1298, ASTM D445 and UNE EN 14370 respectively.

\begin{tabular}{lcccc}
\hline Property & Units & n-Heptane & n-Dodecane & Surrogate \\
\hline Density & $\mathrm{kg} / \mathrm{m}^{3}$ & 679.7 & 745.8 & 802.1 \\
Viscosity & Pas & $5.59 \mathrm{e}-4$ & $1.36 \mathrm{e}-3$ & $1.61 \mathrm{e}-3$ \\
Surface tension & $\mathrm{N} / \mathrm{m}$ & 0.020 & 0.025 & 0.026 \\
Boiling point & $\mathrm{K}$ & 372 & 489 & 453 to 516 \\
\hline Ref. color & - & cyan & blue & magenta \\
\hline
\end{tabular}

\subsection{Hydraulic characterization}

The injection rate measurements were carried out in a standard injection rate discharge curve indicator described in detail by Payri et al. [42]. In order to obtain a good estimation of the average behavior, fifty (50) consecutive injections were carried out at each test condition. The maximum dispersion was minimized to approximately $0.3 \%$ after proper calibration of the equipment.

The spray momentum, on the other hand, is based on the measurement of the impingement force of a spray on a surface normal to the spray axis. This force represents the spray momentum flux which is measured using the test rig described in detail by Payri et al. [43]. In this test rig, the spray is injected into a chamber which can be pressurized with nitrogen up to $9.5 \mathrm{MPa}$ in order to reproduce the pressure during the injection process inside the 
chamber. The impact force of the spray is measured with a piezoelectric pressure sensor previously calibrated and placed at $5 \mathrm{~mm}$ from the nozzle orifice exit. The location and frontal area of the sensor are carefully chosen to ensure full coverage, i.e., spray impingement area $\ll$ sensor area. Pressure inside the chamber is constant and fuel is assumed to deflect perpendicular to the spray axis after impingement. The force measured at the sensor is equal to the axial momentum flux at the orifice outlet or at any other axial location in the spray [43].

\subsubsection{Hydraulic characterization test plan}

The experimental test plan was designed to evaluate the effect of different internal nozzle flow characteristics over the development of macroscopic spray. The different internal nozzle flow conditions are achieved by varying the rail pressure, chamber (back) pressures, and doing this for three fuels with different properties (Table 2). The complete test plan is presented in Table 3. Note that each test point is done for all of the nozzles and fuels. Therefore, a total of 90 different test points were measured. All the experimental results presented in this manuscript are available for download at: http://www. cmt.upv.es/DD01.aspx.

Table 3: Hydraulic characterization test plan.

\begin{tabular}{lll}
\hline Parameter & Value-Type & Units \\
\hline K-factor & $0-1.5$ & - \\
Energizing time & 2500 & us \\
Injector coolant temperature & 343 & $\mathrm{~K}$ \\
Back pressure & $3.0-6.0-9.0$ & $\mathrm{MPa}$ \\
Rail pressure & $30.0-60.0-90.0-150.0-200.0$ & $\mathrm{MPa}$ \\
Number of repetitions per test & 50 & - \\
\hline
\end{tabular}

\subsection{Isothermal spray visualization}

As a first step towards validating spray models, isothermal liquid spray visualization was selected to characterize the macroscopic spray. It is a relatively simple technique that provides highly useful spatial and temporal information to CFD modelers. Moreover, it is widely known that the liquid isothermal spray penetration is closely related to the vapor spray penetration [44]. It has also been proven that if spray models predict correctly the vapor 


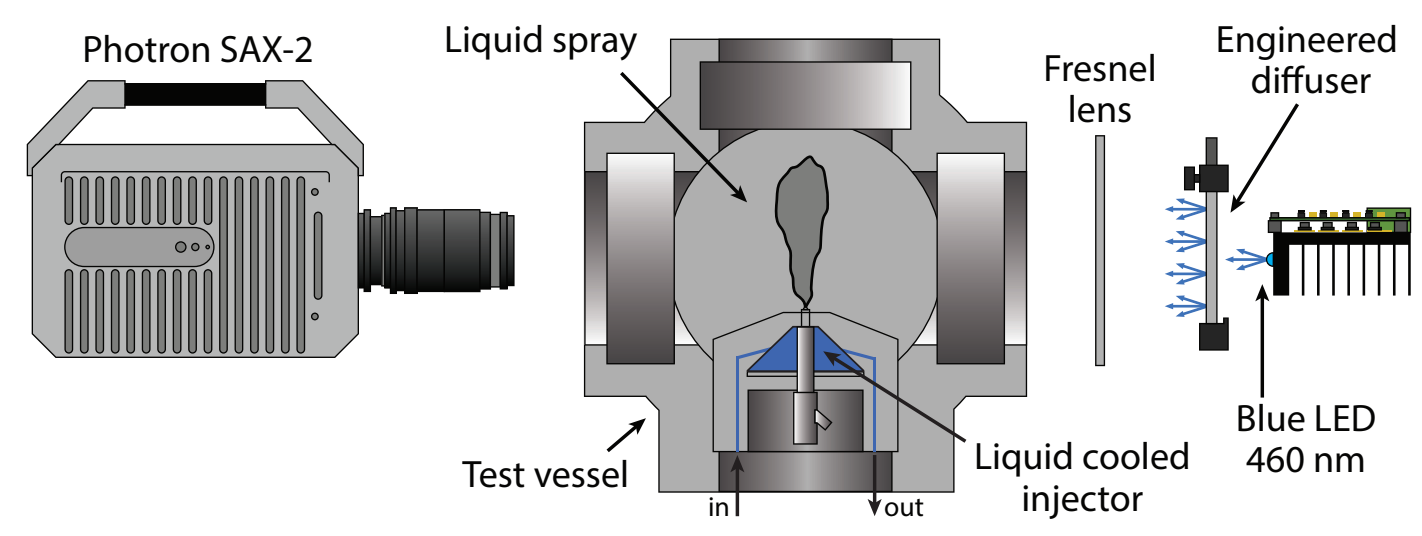

Figure 1: Scheme of the diffused back illumination optical setup.

penetration, they also predict the fuel mixture fraction with adequate accuracy [45]. Thus isothermal liquid spray visualization is a valuable technique that can capture the effects of nozzle flow characteristics, and hence, can also be used to calibrate and evaluate spray models.

\subsubsection{Optical technique and setup}

Figure 1 shows the optical setup that employs diffused back illumination technique. The light emitted by the source is forced through a diffuser and field lens before going into the chamber. Inside the chamber, light passes through the liquid core with refractive index much greater than the surrounding gas. This difference in refractive indices deflects light strongly such that the beams entering the liquid core are not captured by the camera which in turn renders dark spots on the image at those corresponding locations. While this technique itself has been long utilized visualizing liquid diesel sprays $[17,18,46,47,48]$, recent introduction of a high speed pulsed lightemitting diode (LED) light source has made this optical setup/technique the best choice for liquid spray visualization for single hole nozzles [49, 50, 51]. Current high-speed camera capabilities in combination with a high-speed pulsed light source - with a controlled pulsed duration of $50 \mathrm{~ns}$ - produce images significantly sharper than any continuous light source or flash type light source option, and reduces the actual timing uncertainties of the image acquired.

In all visualization experiments performed in this study, the camera frame rate was set to $160 \mathrm{kHz}$. Sampling rate was a high priority, but it was also 
desired to have a field of view (FOV) of at least $60 \mathrm{~mm}$ with an acceptable spatial resolution. The final setup features and image of 512 pix $\times 112$ pix with a spatial resolution of $7.1 \mathrm{pix} / \mathrm{mm}$. The shutter time duration was set to $2.5 \mu \mathrm{s}$, although this is not determinant since the effective exposure timing is given by the LED pulse duration. The effective LED pulse duration was set to $50 \mathrm{~ns}$ and the time-phasing between the camera clock signal and the LED pulse signal was fixed at $500 \mathrm{~ns}$, making sure that the complete LED pulse is captured during the exposure window.

\subsubsection{Image processing}

Each image is processed using an algorithm that detects the spray boundary and computes its associated properties. The background is calculated as an average of all the images acquired before start of injection (SOI). After the start of injection, this background is subtracted from each image frame and the result inverted so that the spray appears as a bright object against dark background. Finally, the spray contours are detected by binarizing the image with a pre-selected threshold. The threshold was fixed to $12 \%$ of the dynamic range of the image. The procedures followed by the algorithm after the binarization to complete the contour detection are explained in detail by Payri et al. [52].

Note that in this isothermal setup, the background is practically constant during the entire injection event due to absence of large temperature and density gradients. This results in a smooth, diffuse background and since the light pulse duration is short, there is little incertitude in detecting the spray boundary. Hence, a relatively large threshold was preferred to guarantee the quality of the boundary detection and ensure robustness against perturbations that result from partial beam steering or local density gradients in the region right next to the spray. Figure 2-top shows an example of a spray boundary detected by the algorithm plotted over the original image, where the dashed line indicates the actual spray axis. Figure 2-bottom presents the normalized intensity profile along the spray axis. The steep and sharp intensity drop at the spray tip is the result of combining a high speed pulsed light source, with very short pulse duration, relatively low chamber temperatures $\left(25^{\circ} \mathrm{C}\right.$ to $\left.40^{\circ} \mathrm{C}\right)$ and temperature gradients, and good optical quality of the optical image acquisition setup.

Now it is possible to estimate the spatial uncertainty in spray boundary detection due to the threshold criteria. Figure 2-bottom shows the intensity thresholds calculated in that particular image for $12 \%$ (blue dashed line) and 


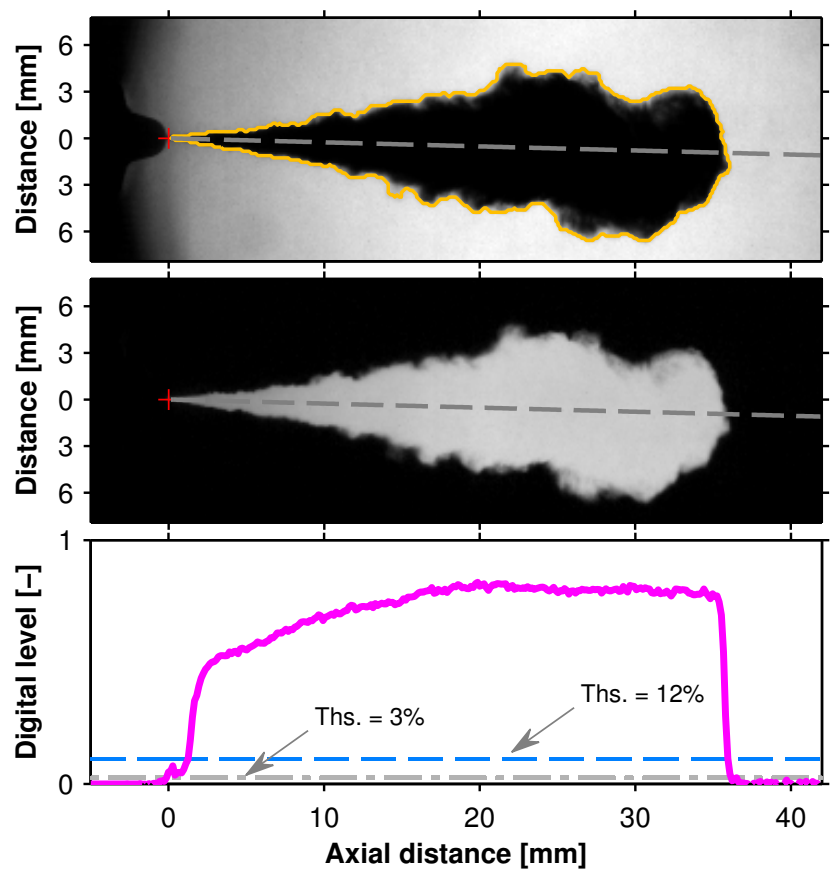

Figure 2: Original image with the spray boundary detected (top), actual image as processed (center) and normalized intensity profile along the spray axis (bottom). The image to be processed comes from background subtraction and inversion. The red cross indicates the nozzle outlet location. The particular frame shown is at $534 \mu \mathrm{s}$ after SOI, the nozzle is $k 0$ injecting the Surrogate fuel, rail pressure is $200.0 \mathrm{MPa}$, and back pressure is $6.0 \mathrm{MPa}$, which corresponds to an ambient density of $66.3 \mathrm{~kg} / \mathrm{m}^{3}$. 


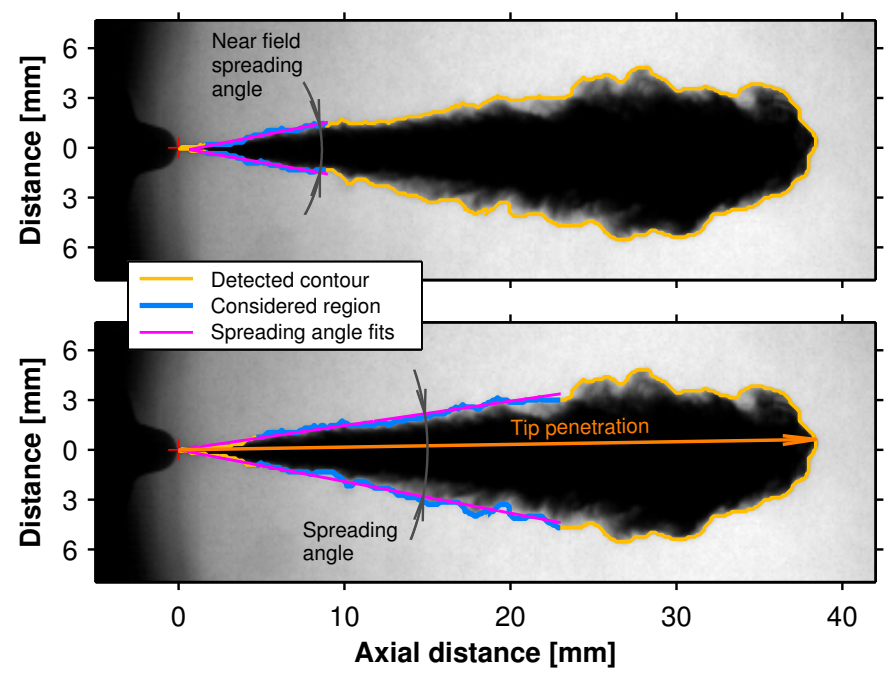

Figure 3: Spray characteristics extracted by the image processing algorithm. The top part illustrates the near field spreading angle estimation, while the bottom part depicts the spray tip penetration and spray spreading angle estimation. The red cross indicates the outlet orifice location. The particular frame shown is at $302 \mu \mathrm{s}$ after SOI, the nozzle is $k 0$ injecting the Surrogate fuel, rail pressure is $200.0 \mathrm{MPa}$, and back pressure is $2.0 \mathrm{MPa}$, which corresponds to an ambient density of $22.8 \mathrm{~kg} / \mathrm{m}^{3}$.

$3 \%$ (light gray dash-dot line) of the dynamic range. The points at which these lines intersect the intensity profile near the spray tip correspond to the spray boundary location detected for those threshold criteria. It is important to note that the $12 \%$ blue dashed line crosses the intensity profile near the point where the slope starts to decrease, as the curve starts to become tangent to zero. The objective is to maximize sensitivity by lowering the threshold, but at the same time, to set a value that permits the robust detection of the first real physical trace of the liquid phase and not to pick up artificial signals. If the threshold is not set high enough, background camera sensor noise or beam steering - both which may affect the estimated intensity profile near the bottom-right area - could bias the spray boundary detection, rendering an over-estimated liquid spray penetration. Therefore, a compromise must be met, and evaluated for all test conditions, which resulted in the selection of $12 \%$ as a well suited value.

Once the spray contour is detected at a particular frame, spray characteristics are extracted for analysis. Figure 3 illustrates a single frame as 
captured by the camera, with the detected contour plotted over and the spray characteristics indicated. The spray tip penetration is the distance measured from the nozzle outlet to the furthest point in the contour detected (Figure 3-bottom). The near field spreading angle is the angle included between two linear fits performed to the spray contour detected within $1.5 \mathrm{~mm}$ and $9 \mathrm{~mm}$ axially measured from the outlet orifice. Note that these fitted lines are not forced to go through the nozzle outlet, as illustrated by the top part of Figure 3. The spreading angle is the angle included between two lines that originate at the outlet orifice and are fitted to the spray contours detected between $12 \%$ and $60 \%$ of the spray tip penetration calculated at that time frame, as indicated by the bottom part of Figure 3 .

\subsubsection{Spray visualization test plan}

The test plan is presented in Table 4, it consists of four rail pressures and three back pressures (thus, ambient densities), for each nozzle. The energizing time was fixed to $2500 \mu \mathrm{s}$ in order to have an injection event long enough to enable the study of a stabilized spray. A total of 72 different test points were measured in the visualization experiments. Note that high rail pressures (i.e., 150.0 MPa and 200.0 MPa) combined with low back pressures (i.e., 2.0 MPa and 3.0 MPa) are expected to produce conditions that choke the mass flow rate in the cylindrical nozzle $k 0$ due to strong cavitating regimes $[18,19,53,54,55]$. Still, this nozzle is expected to cavitate well before the mass flow rate choke conditions $[39,54,55]$. All the experimental results presented in this manuscript are available for download at: http://www . cmt . upv . es/DD01. aspx.

Table 4: Spray visualization test plan.

\begin{tabular}{lll}
\hline Parameter & Value-Type & Units \\
\hline K-factor & $0-1.5$ & - \\
Energizing time & 2500 & us \\
Injector coolant temperature & 343 & $\mathrm{~K}$ \\
Back pressure & $2.0-3.0-6.0$ & $\mathrm{MPa}$ \\
Rail pressure & $60.0-90.0-150.0-200.0$ & $\mathrm{MPa}$ \\
Number of repetitions per test & 8 & - \\
\hline
\end{tabular}




\section{Results}

\subsection{Hydraulic characterization}

In this section, the hydraulic characterization results are presented. Both the transient measured signals and their associated steady values are important to the overall analysis.

\subsubsection{Rate of injection}

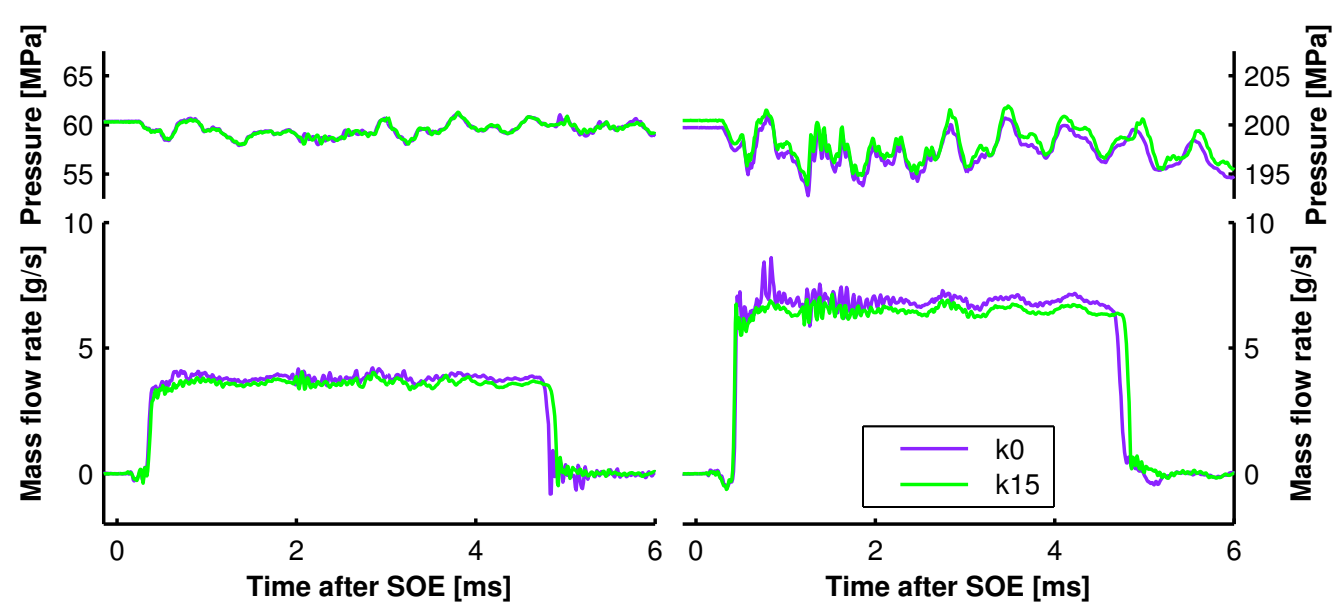

Figure 4: Rail pressure (top) and injection rate signals (bottom) measured for the two nozzles at rail pressures of $60.0 \mathrm{MPa}$ (left) and $200.0 \mathrm{MPa}$ (right). In this case, the injected fuel is n-heptane and the back pressure is $6.0 \mathrm{MPa}$.

Figures 4 and 5 depict examples of rate of injection signals comparing nozzles and fuels respectively. The lowest and highest rail pressures are also shown in each case to illustrate its effect for all nozzles and fuels. The rates of injection measured present the expected responses to both rail and back pressure. Consistently throughout the test matrix, nozzle $k 15$ presented slightly lower stabilized mass flow rates, due to its smaller diameter. This is also summarized in Figure 8, where all test conditions are presented.

Figure 5 shows higher rate of injection for the Surrogate fuel, followed by n-dodecane and finally n-heptane. This order is consistent with the corresponding fuel densities, in agreement with results found in the literature $[56,39,57]$. Also, for the same energizing time, different fuels render different effective injection durations. If the energizing time is long enough, the needle 
lift reaches the mechanical limit which implies that the needle closing time is proportional to the viscosity of the fuel [58].

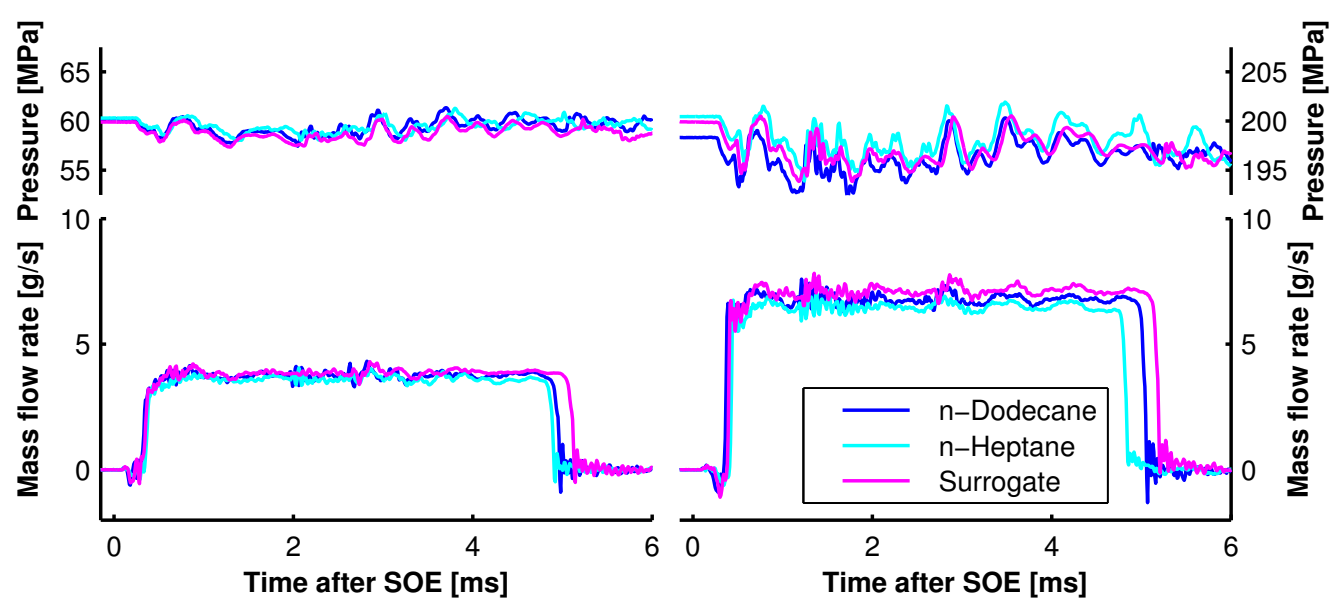

Figure 5: Rail pressure (top) and injection rate signals (bottom) measured for the three fuels at rail pressures of $60.0 \mathrm{MPa}$ (left) and $200.0 \mathrm{MPa}$ (right). In this case, the nozzle is $k 15$ and the back pressure is $6.0 \mathrm{MPa}$.

\subsubsection{Spray momentum}

Analogous to the rate of injection results presented in Figures 4 and 5, Figure 6 shows that nozzle $k 15$ presents lower momentum flux due to its smaller diameter, and this was observed throughout the complete test matrix, as depicted by Figure 9 . Note how the difference between nozzles increases with rail pressure, since the contribution by the flow area is then amplified by the pressure delta. On the other hand, Figure 7 illustrates how the momentum flux is independent of the fuel utilized [56]. Moreover, note how the n-heptane injection is shorter overall, as explained before. In the case of $30 \mathrm{MPa}$ of rail pressure the effective injection duration time is more similar between fuels, which could suggest that the needle is not reaching its mechanical limit for lift in neither of these cases, so the effective injection duration is a combination of pressure differentials over the needle, fuel viscosity and fuel density [58].

\subsubsection{Hydraulic analysis}

From the signals presented in Figures 4 to 7, time-averages can be calculated from the stabilized table-top region of each signal. This way, results of 


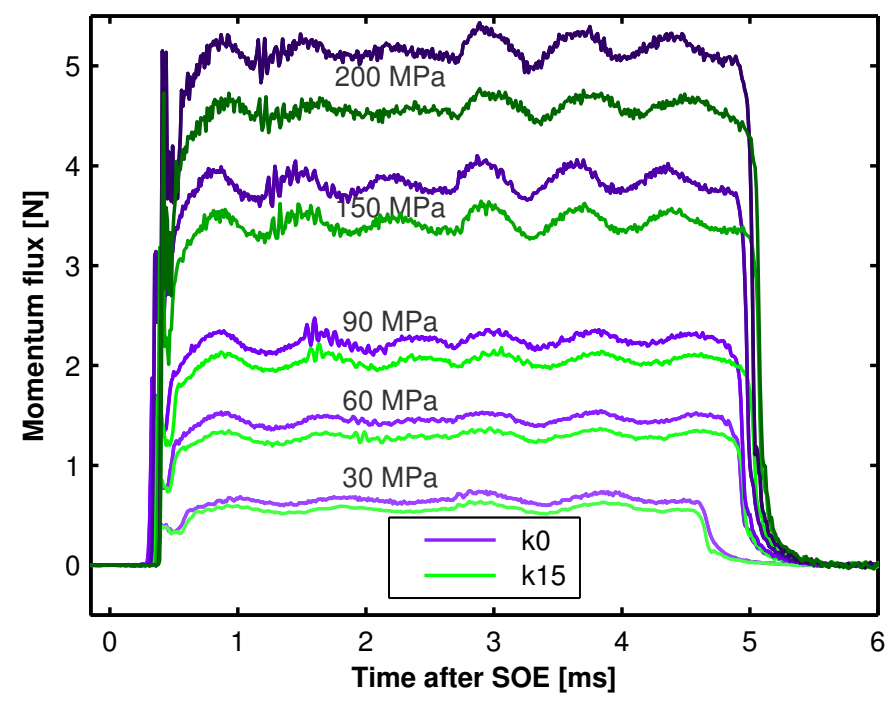

Figure 6: Momentum flux signals measured for the two nozzles at all rail pressures. In this case, the fuel is $\mathrm{n}$-dodecane and the back pressure is $6.0 \mathrm{MPa}$.

the complete test matrix can be condensed into a single figure for particular analysis.

Figure 8-top shows stabilized mass flow rates as a function of the squared root of the pressure drop through the nozzle. Note how values are ordered with fuel density, and how the conical nozzle $k 15$ stays lower in absolute mass flow rate values in comparison to the cylindrical nozzle $k 0$, as explained before. Note that sub-groups of points correspond to each of the rail pressures tested, and within a group, there are three back pressures distinguished by different shades of the corresponding color. Figure 8-bottom shows the discharge coefficients, which are normalized by fuel density and nozzle diameter [43]. Here, the cylindrical nozzle shows a strong cavitating behavior, evidenced by the drastic reduction in the discharge coefficient, especially as the pressure difference is increased by reducing back pressure. Note that for high rail pressure cases the flow is completely collapsed for the cylindrical nozzle $k 0$ (i.e. all discharge coefficient points are grouped closely) while the low rail pressure cases show symptoms of flow collapse only when back pressure is decreased.

Figure 9 illustrates stabilized momentum flux measurements as a function of the pressure differential through the nozzle, comparing nozzles and fuels. 


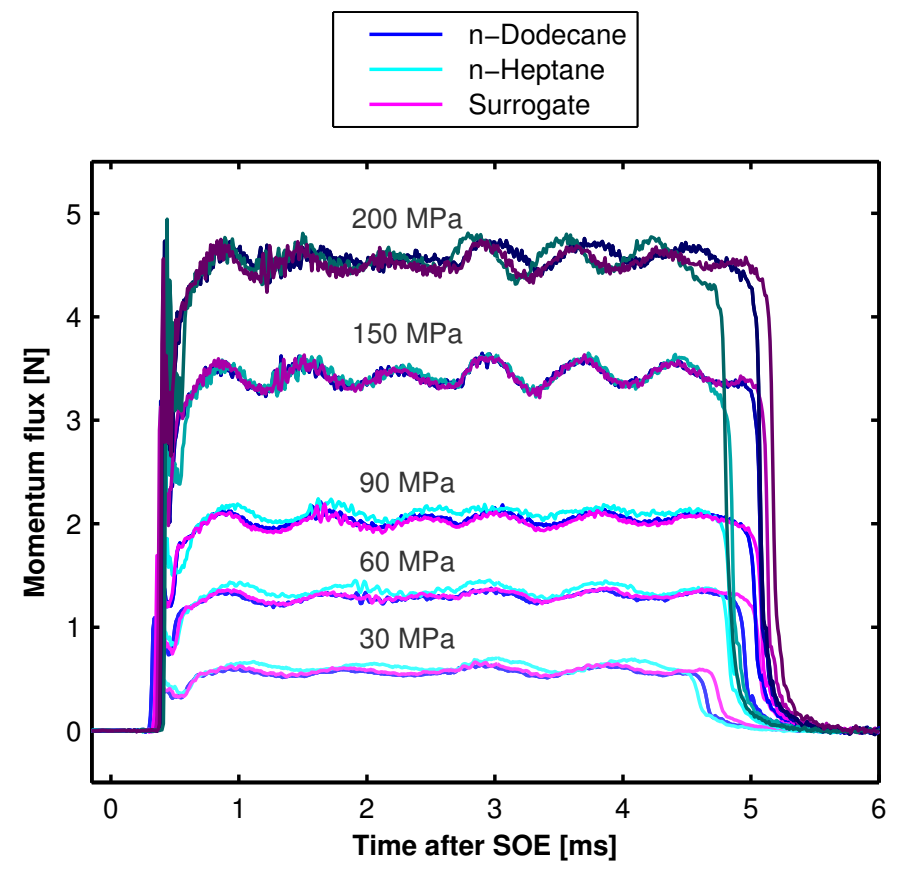

Figure 7: Momentum flux signals measured for the three fuels at all rail pressures. In this case, the nozzle is $k 15$ and the back pressure is $6.0 \mathrm{MPa}$.

As seen previously in Figure 7, momentum flux is generally independent of the fuel properties. Also as already commented in Figure 6, nozzle $k 15$ shows lower momentum flux values due to its smaller diameter, and this difference increases with rail pressure.

Utilizing both the rate of injection and the momentum flux measurements, it is possible to estimate the effective flow velocity and area coefficient at the outlet orifice [43]. Figure 10-top shows the effective velocities estimated as a function of the squared root of the pressure drop through the nozzle. Note how effective velocity values are ordered inversely with the fuel density, which is expected from the rate of injection and momentum flux results. Finally, Figure 10-bottom shows area coefficients, where the reduction in cross-section originated by cavitation is evidenced for the cylindrical nozzle $k 0[43,19,39]$. 


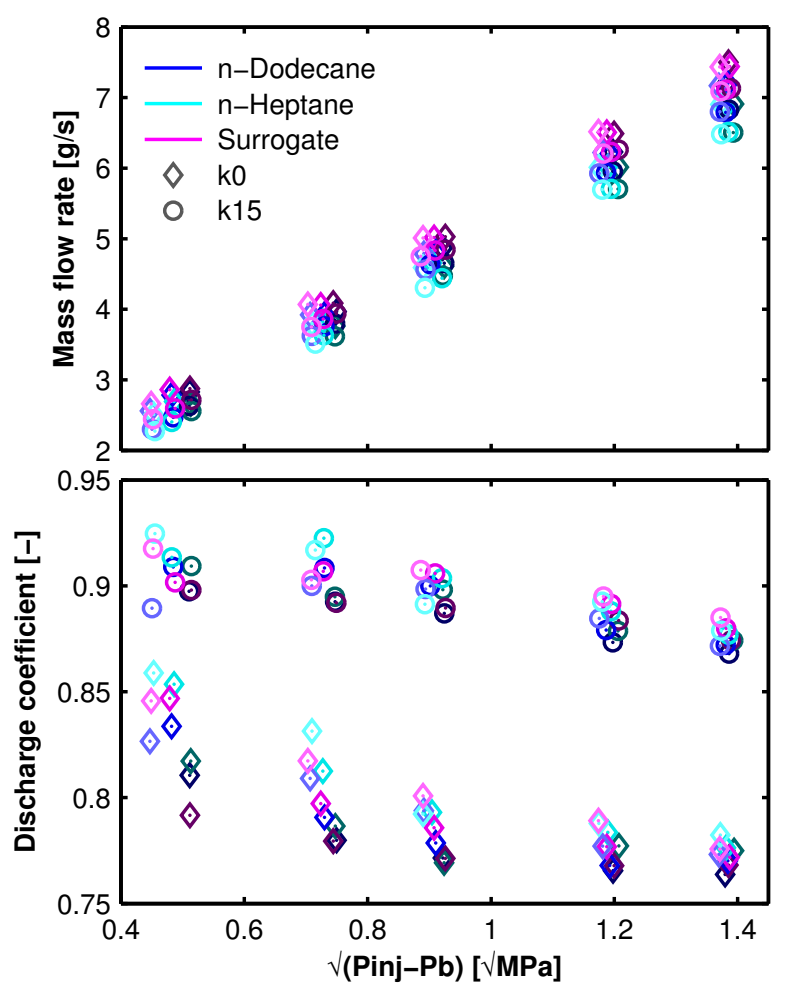

Figure 8: Steady rate of injection (top) and discharge coefficient (bottom) as a function of the pressure drop across the injector for all test conditions. Note that fuels are denoted by color while nozzles are indicated by symbols. Note that sub-groups of points correspond to each of the rail pressures tested, and within a group, there are three back pressures distinguished by different shades of the corresponding color.

\subsection{Isothermal spray visualization}

\subsubsection{The effect of nozzle geometry on spray formation}

Figure 11 shows a subset of the full test matrix results obtained from the experiments. The effects of injection pressure (top), and back pressure (bottom) on spray development are shown for two different nozzles. The different test conditions are indicated by symbols. Each curve depicts the spray penetration as a function of time obtained by ensemble averaging multiple consecutive injection events, following the same rolling-average algorithm described by Payri et al. [52], utilizing a window size of $56 \mu \mathrm{s}$. The algorithm is very similar to an Savitzky-Golay digital filter but accounting for multiple digital signals (the multiple test repetitions performed). 


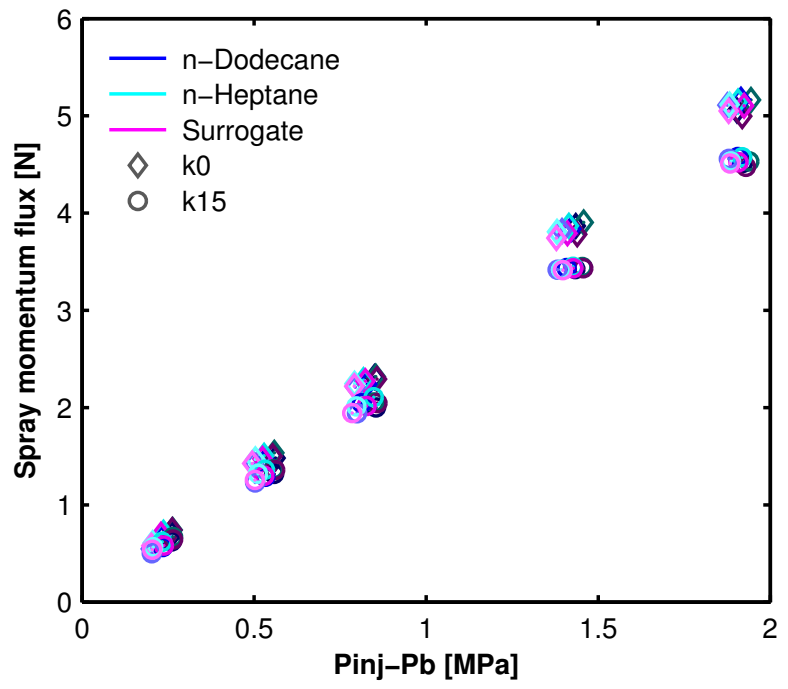

Figure 9: Steady momentum flux values as a function of the pressure drop across the injector for all test conditions. Note that fuels are denoted by color while nozzles are indicated by symbols.

The ensemble-averaged signal is then phased in time with the SOI timing, which was estimated by performing a linear fit to the raw data set found in the first $5 \mathrm{~mm}$ of the penetration curves of all repetitions, for a given set of test conditions. A good estimation of the actual SOI for each test conditionwhich is enhanced by the fast acquisition rates and the short illumination pulse length provided by the fast LED - facilitates the time-phasing of the penetration curves for comparison.

The top part of Figure 11 shows that rail pressure impacts spray penetration right from the start of injection, while the bottom part shows that ambient density impacts it only at later stages (time $>0.1 \mathrm{~ms}$ ) of spray where aerodynamic interaction with surrounding gas becomes important. In spite of lower mass flow rate and momentum flux, the conical nozzle $k 15$ shows faster tip penetration rates in the later stages of the spray (time $>0.1 \mathrm{~ms}$ ) when compared to the cylindrical nozzle $k 0$. This occurs because of the turbulent velocity profiles produced by the cylindrical nozzle [59], that enhance spray mixing and momentum exchange which in turn leads to slower tip penetration. Hence, at higher injection pressures and lower ambient density (Figure 11-top), where the effect of aerodynamic drag loses importance, the difference in the penetration of sprays produced by the two nozzles is reduced. 

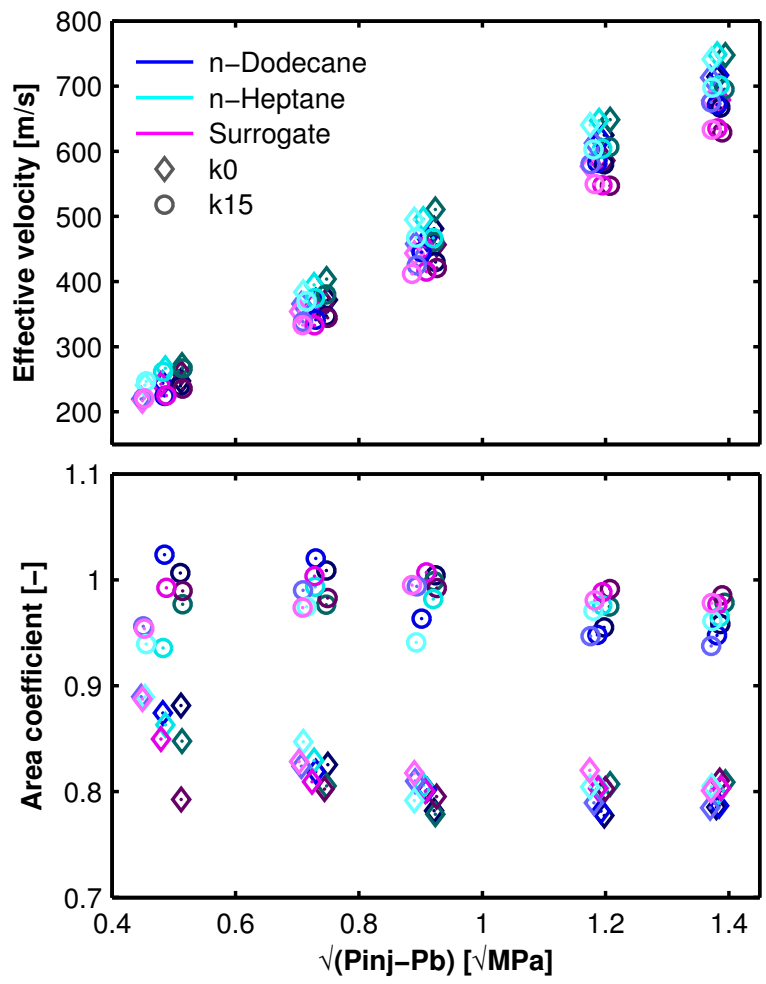

Figure 10: Steady effective outlet velocity (top) and area coefficient (bottom) as a function of the pressure drop across the injector for all test conditions. Note that fuels are denoted by color while nozzles are indicated by symbols.

This is also due to the increasingly higher momentum flux from nozzle $k 0$ at higher injection pressures (see Figure 9) in comparison to nozzle $k 15$. Consequently, higher ambient density cases shown in the bottom part of Figure 11 show greater difference between the two nozzles. These conditions allow time for the aerodynamic interactions to develop, and turbulent velocity profiles in the outlet orifice become more important to the gas entrainment process, liquid break-up is enhanced and the smaller droplets exchange momentum more efficiently with the ambient gas. Note that similar results for different nozzles were reported previously $[4,6]$. In both studies, authors perform numerical simulations of the liquid spray for cylindrical and conical nozzles, showing that the penetration curves start to diverge after a certain time has passed and aerodynamic interaction has played its part, even though the effect of nozzle geometry is just introduced as boundary conditions at the 

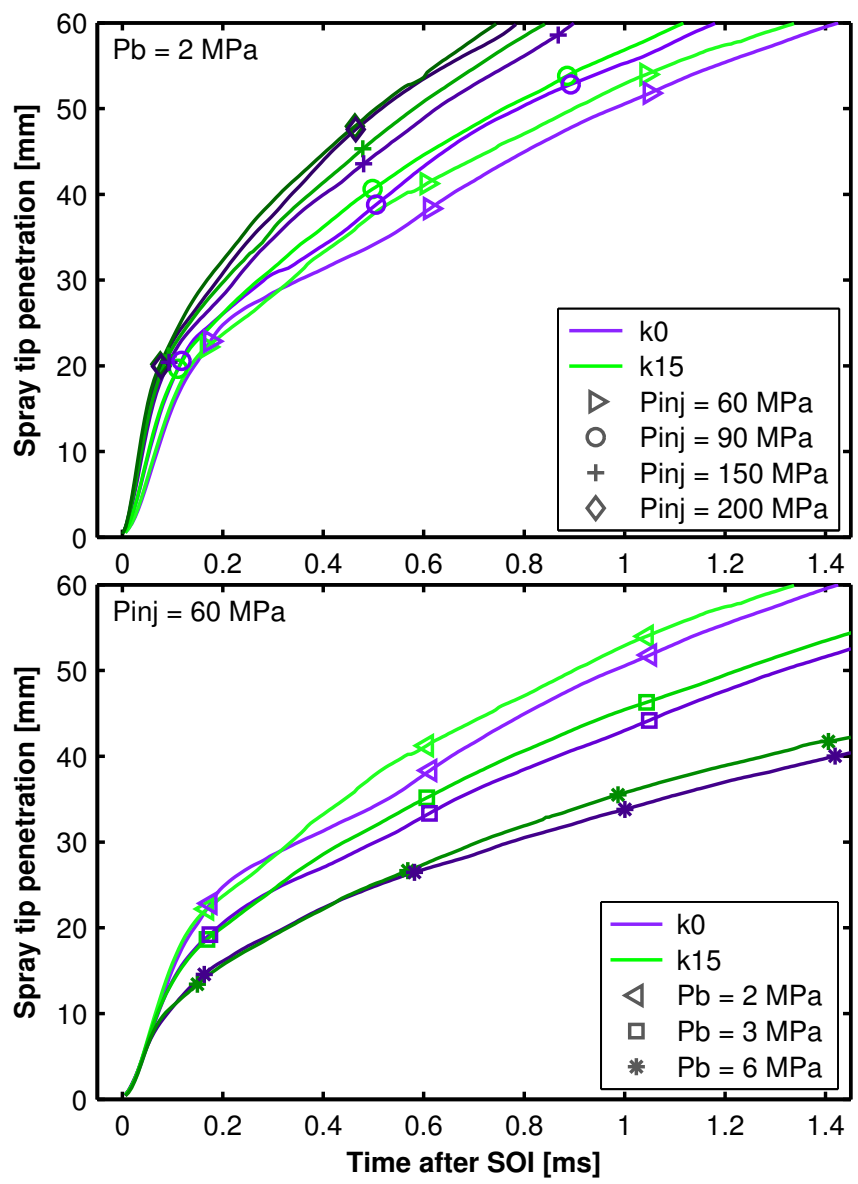

Figure 11: The effect of nozzle geometry on spray tip penetration for different rail pressures at a back pressure of $2.0 \mathrm{MPa}$ (top), and different back pressures at a rail pressure of $60.0 \mathrm{MPa}$ (bottom). The three different back pressures result in ambient densities of $22.8 \mathrm{~kg} / \mathrm{m}^{3}, 33.0 \mathrm{~kg} / \mathrm{m}^{3}$ and $66.3 \mathrm{~kg} / \mathrm{m}^{3}$ respectively. In this case, the fuel presented is the Surrogate fuel.

orifice interface. Note that Montanaro et al. [6] observed the same trend in their experimental results, presented in the same paper but detailed further by Zhang et al. [20]. Finally, it is important to point out that the difference between the behavior of the two nozzles is not independent of fuel, and is smaller for n-dodecane in comparison to the Surrogate fuel case shown in Figure 11. Nevertheless, the trends observed are similar.

Further analysis can be made to reach a better understanding of the ef- 


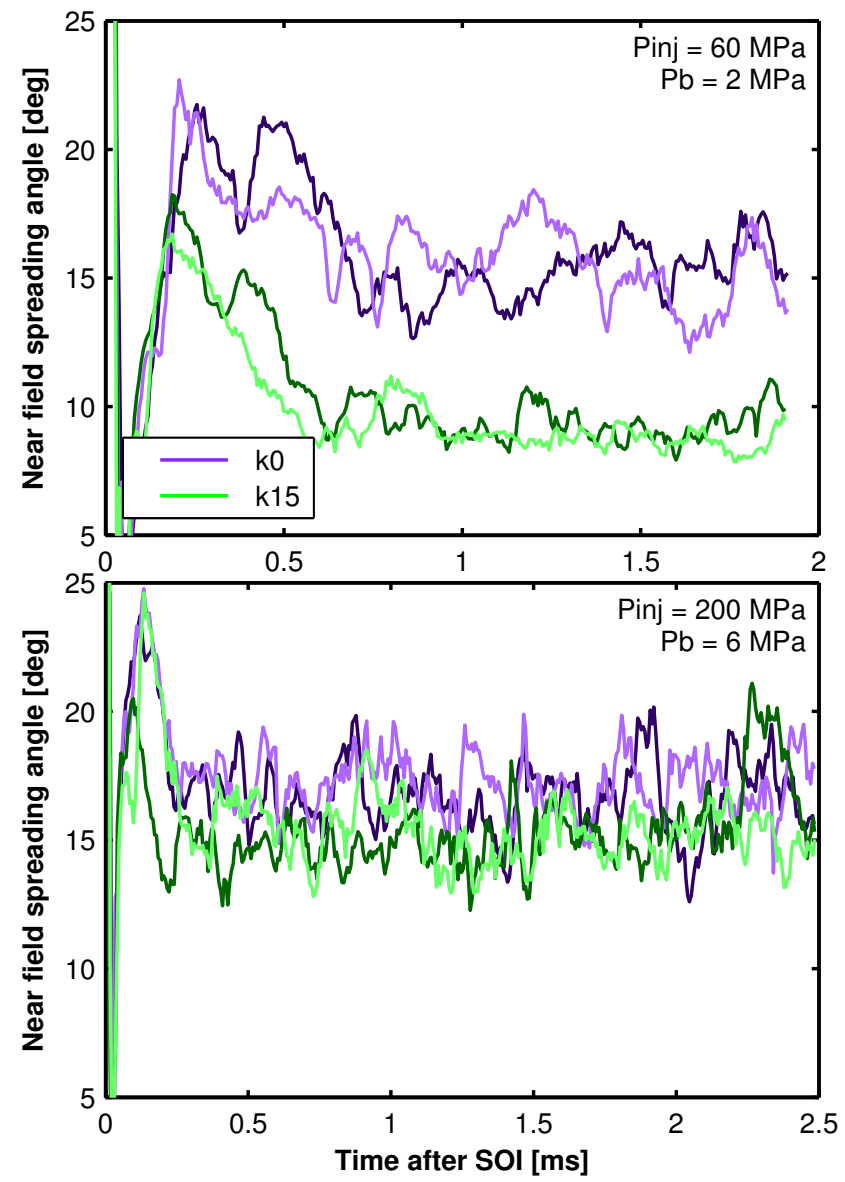

Figure 12: The effect of nozzle geometry on the near field spray spreading angle for two particular test repetitions at rail and back pressures of $60.0 \mathrm{MPa}$ and $2.0 \mathrm{MPa}$ (top), and 200.0 MPa and 6.0 MPa (bottom). Two different test repetitions are shown at each test condition, distinguised by color shades of the base nozzle color. The case presented corresponds to the Surrogate fuel.

fects of the nozzle geometry over the spray formation. For example, Figure 12 presents the near field spreading angle for two particular test repetitions. The near field spreading angle reported is defined in section 2.3.2, and illustrated in the top part of Figure 3. It is important to point out that the fits are not forced to go through the nozzle outlet. Even though this is common practice when measuring large penetration-scaled angles [18, 47], this approach attenuates local fluctuations, which are intended to be shown in this 
analysis. Note that in the case of Figure 12 no repetition-average behavior is presented, but instead two randomly selected test repetitions are shown. This permits the illustration of steady state trends along with transient effects such as time resolved fluctuations. The steady state behavior of these signals can be summarized in terms of time-averages of spreading angles, and the fluctuations can be quantified in terms of the standard deviation.

Figure 12 shows a clear difference in the near field spreading angle behavior produced by the two nozzles. Note that all signals fluctuate significantly, which is the result of the turbulent interaction between the liquid spray and the surrounding gas. In general, the cylindrical nozzle $k 0$ features larger steady state near field spreading angles and fluctuations throughout the complete test matrix. In particular, the top part of Figure 12 shows one of the scenarios where the difference is largest-39.6\% difference between the two nozzles for the steady angles and $50.0 \%$ for the fluctuations - while the bottom part of Figure 12 presents one of the cases where the difference is smallest - still, $10.2 \%$ for the steady angles and $17.0 \%$ for the fluctuations. Similar results have been reported previously. Han et al. [10] studied the effect of nozzle geometry over the microscopic spray development, showing that cylindrical nozzles produce larger fluctuations in spreading angle when compared to conical nozzles. Unfortunately, details on how the angle reported is measured and the repetition-average behavior are not given. Blessing et al. [11] also presented spreading angles of the microscopic spray, showing that cylindrical nozzles (and also, diverging nozzles) produce larger micro-spreading angles than conical nozzles, but the acquisition rate utilized for the study is not sufficient to properly detect or quantify fluctuations. On the other hand, Payri et al. [18] presented penetration-scaled spreading angles showing also that cylindrical nozzles render larger spreading angles in comparison to conical nozzles. Interestingly, both studies also show an effect of the nozzle geometry over the macroscopic spray tip penetration, but since the penetration rates presented are very similar between the different nozzles, and the differences reported are very small, this trend may be strongly influenced by the correct detection of the SOI timing and the time-phasing of each penetration curve, which is more uncertain at the acquisition rates of $20 \mathrm{kHz}$ utilized in both cases. A comparable result was also presented by Liu et al. [16], in which two cylindrical nozzles - with and without hydrogrinding - are compared and their results show larger micro-spreading angles for the nozzle without hydro-grinding. Even though each one of these studies is different, with particular aims, nozzles, and optical techniques, one con- 
clusion remains: turbululent velocity profiles, caused by geometrical features inside the nozzle, indeed affect the liquid spray in terms of dispersion, which includes spreading angle and fluctuations.
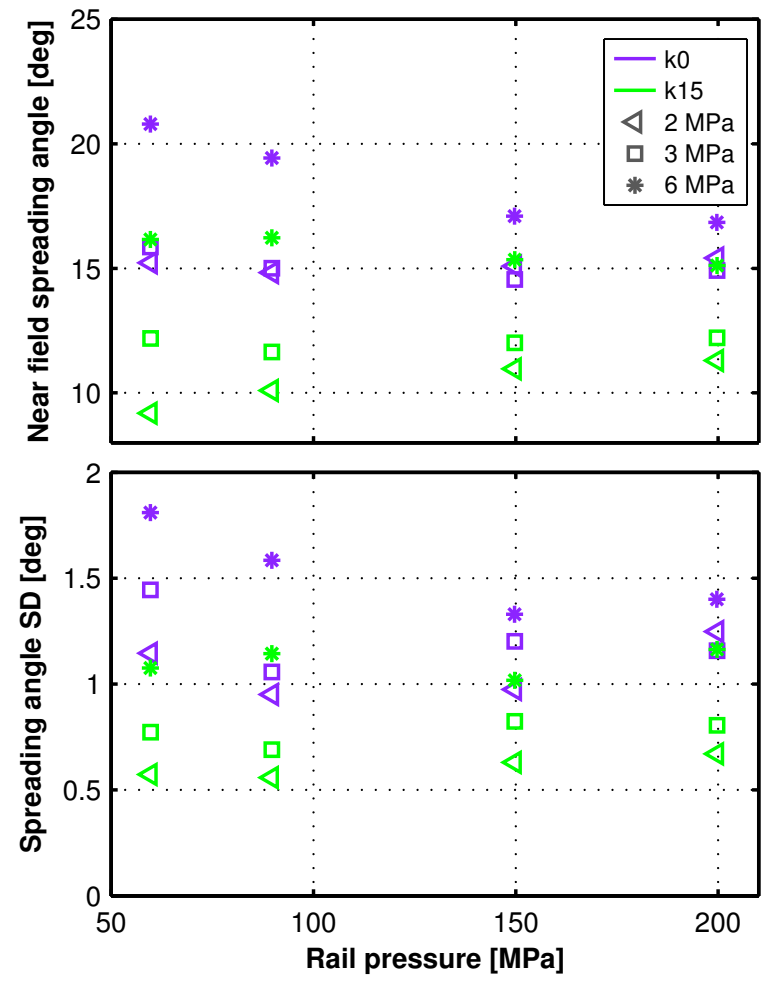

Figure 13: Time-averaged near field spray spreading angles (top) and their standard deviation (bottom) for all test conditions, nozzles and the Surrogate fuel. The values reported are calculated by averaging the raw data from all test repetitions from $0.8 \mathrm{~ms}$ after SOI to the end of the signals.

Following the analysis of the time-resolved spreading angles, a wider scope analysis can be made if these time-averaged values are synthesized into one single figure. Figure 13-top shows the time-averaged spreading angle values for the complete test matrix. The percentage differences reported previously correspond, then, to just two pairs of points within this figure. Note that, the effect of the nozzle geometry is stronger than the effect of a considerable increase in ambient density, which is well known to be a determinant parameter controlling spreading angle $[48,60]$. Figure 13-top clearly shows that the cylindrical nozzle $k 0$ renders larger spreading angles throughout the 
test matrix, as affirmed before. In comparison to the conical nozzle $k 15$, the cylindrical nozzle $k 0$ shows an opposite trend of increase in spreading angle with rail pressure. While the conical nozzle shows a monotonic increase in spreading angle with back pressure (thus, ambient density), the cylindrical nozzle $k 0$ has two cases with $2 \mathrm{MPa}$ and $3 \mathrm{MPa}$ back pressure, where this monotonicity is not present. In these two cases where the ambient densities are close, cavitation and radial velocity profiles caused by turbulence inside the nozzle may play a more important role in the final spreading angle produced $[61,53,62]$ than the actual density. Finally, it must be noted that the rail pressure was not found to significantly influence the near-field spreading angle reported here, which has also been seen previously by other authors $[63,60,64,65]$. Still, it must be pointed out that in cases such as these, detailed time-resolved numerical simulations of this problematic would surely help to better understand the observed trends, especially when comparing the response of each nozzle to the different pressure differentials.

Similar analysis can be made for the dispersion of the signals from which the time-averaged steady state values presented in Figure 13-top are obtained, as depicted in Figure 13-bottom. These points are, therefore, measurements of the fluctuations of the near field spreading angle at each test condition and nozzle. The results show that the cylindrical nozzle $k 0$ presents higher fluctuations around the mean spreading angle values throughout the test matrix. However, its response along the test matrix - both for rail and back pressures - does not show a clear trend. To this end, it must be pointed out that since these sprays are strongly turbulent, this kind of signals are seldom self similar and, therefore, the standard deviation measurements may need longer signal lengths than those utilized here, to better show the trends for the cavitating nozzle $k 0$. The behavior of the conical nozzle $k 15$ seems to be more consistent along the rail and back pressure spectrum: fluctuations do not seem to be strongly affected by rail pressure, while increasing back pressure - mainly, chamber density - indeed increases the fluctuations. Overall, this is a very interesting result because it suggests that, even though outlet velocities increase with rail pressure - and thus, the Reynolds number - it seems to end up not playing a key role in the spray angle magnitude and fluctuations. This is one of the many cases where detailed nozzle-spray numerical simulations can provide valuable information on the fundamental driving mechanisms behind such behavior. 


\subsubsection{Spray formation for different fuels}

The effect of nozzle geometry also depends on the physical properties of the fuel. Figures 14 and 15 present results of select test conditions, to illustrate how nozzles $k 15$ and $k 0$, respectively, respond to the different fuels. In general, n-heptane shows slower penetration rates throughout the test matrix, which is expected due to the lower density, viscosity and surface tension, all which enhance liquid breakup and momentum exchange between fuel and ambient gas, as reported by Crua et al. [66] and later Ding et al. [67] in their microscopic studies. Figure 14 shows that for non-cavitating conditions the Surrogate spray penetrates faster than the n-dodecane spray. Featuring slightly higher density and comparable viscosity and surface tension, the Surrogate liquid spray conserves momentum better than the n-dodecane spray. Similar observations were reported by Desantes et al. [56] and Park et al. [68] with respect to fuel density. However, that conclusion does not hold for the cylindrical nozzle $k 0$, as seen in Figure 15. In these conditions, trends between the sprays produced by the two fuels are inverted, and the n-dodecane spray has the fastest tip penetration.

Since the rest of the variables controlling spray tip penetration are kept constant and controlled between nozzles, the different spray tip penetration responses observed for n-dodecane and Surrogate fuels should be reflected in spray spreading angle [47, 48]. Figure 16 shows penetration-scaled spreading angles to asses the former conclusion. Reported values correspond to the spray spreading angle defined in section 2.3.2, and illustrated in the bottom part of Figure 3. n-Heptane sprays feature the largest macroscopic spreading angles through the whole test matrix, in agreement with the spray penetration curves presented in Figures 14 and 15, due to its lower density, viscosity and surface tension $[66,67]$. Also in agreement with the penetration results, the trends between n-dodecane and Surrogate sprays depend on the nozzle, or the cavitation regime. For the cylindrical nozzle $k 0$ the Surrogate spray produces larger spreading angles in comparison to the n-dodecane spray, while the opposite holds for nozzle $k 15$. Note that for each fuel and nozzle, these spreading angles are ordered with back pressure and thus, ambient density, as found in the literature $[44,48]$.

\subsubsection{A further analysis on nozzle and fuel effects on spray formation, mix- ing and fluctuations}

Although the macroscopic characteristics of the spray are often quantified as steady state values, the real spray is seldom a steady state process. Even 

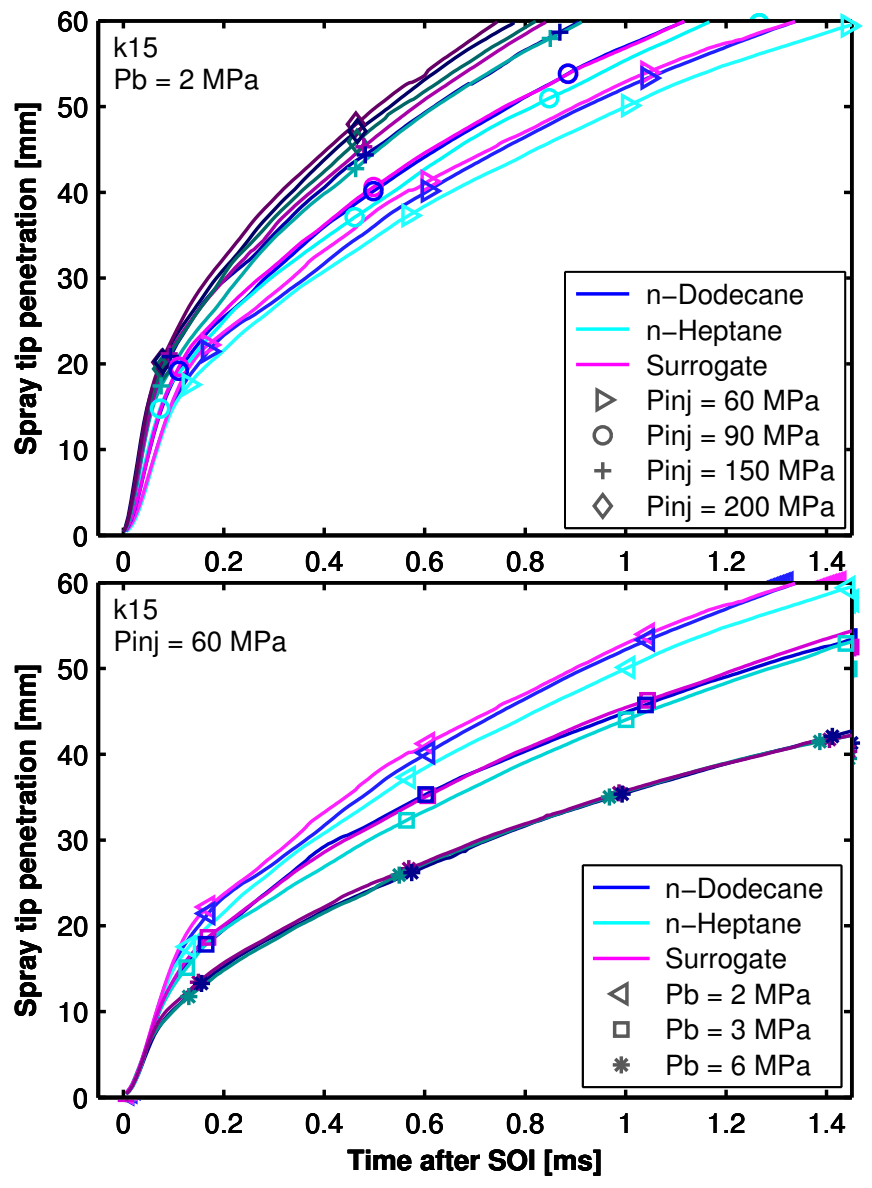

Figure 14: Spray tip penetration for all fuels and different rail pressures at a back pressure of $2.0 \mathrm{MPa}$ (top), and different back pressures at a rail pressure of $60.0 \mathrm{MPa}$ (bottom). The three different back pressures result in ambient densities of $22.8 \mathrm{~kg} / \mathrm{m}^{3}, 33.0 \mathrm{~kg} / \mathrm{m}^{3}$ and $66.3 \mathrm{~kg} / \mathrm{m}^{3}$ respectively. In this case, the nozzle is $k 15$.

for the fully developed "steady" spray, considerable local fluctuations are still present. These fluctuations are evidence of the strongly turbulent mixing process and therefore, differences registered in spray tip penetration are not only explained by "steady" state spreading angles, but also by fluctuations and turbulence, both of which enhance momentum exchange.

Figure 17 shows fluctuation maps of the sprays produced by the two nozzles and three fuels at a particular case of test conditions. The map is calculated as the standard deviation between all binary images of the 

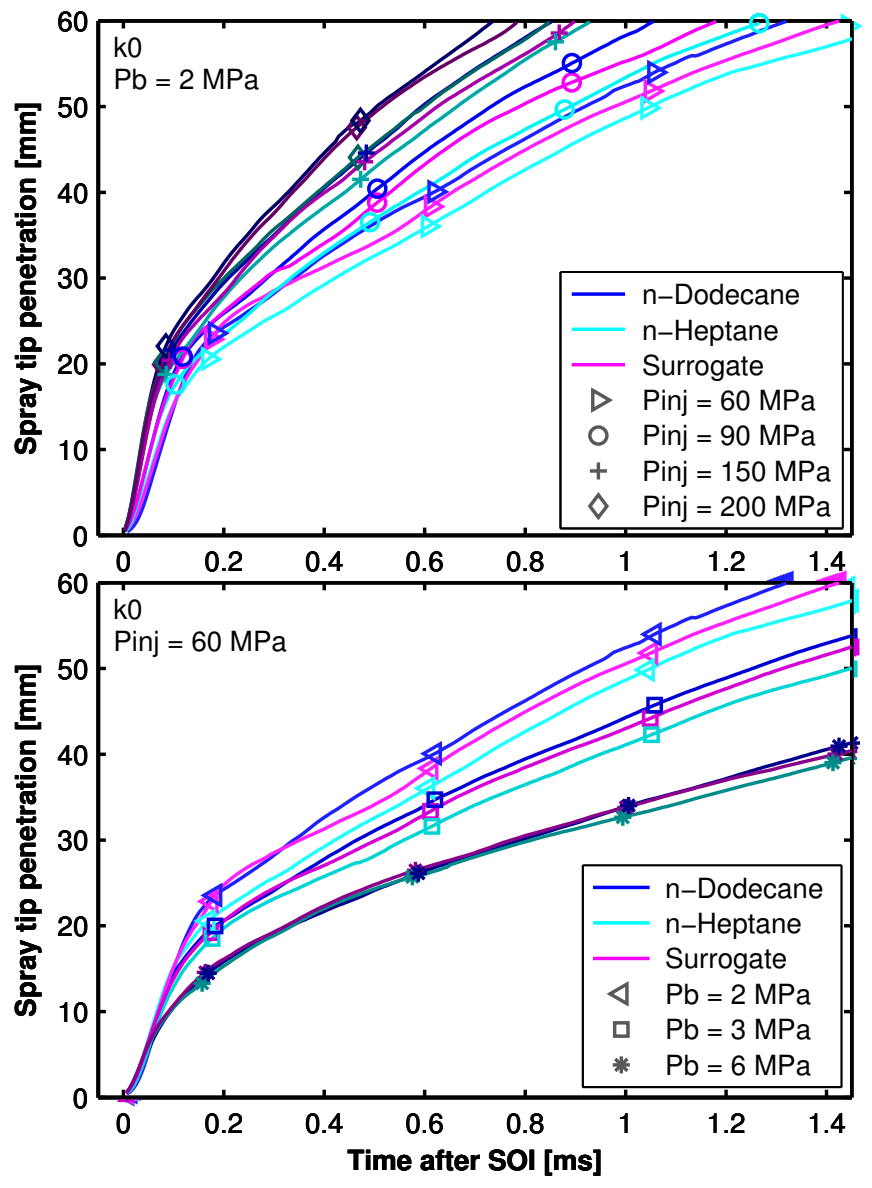

Figure 15: Spray tip penetration for all fuels and different rail pressures at a back pressure of $2.0 \mathrm{MPa}$ (top), and different back pressures at a rail pressure of $60.0 \mathrm{MPa}$ (bottom). The three different back pressures result in ambient densities of $22.8 \mathrm{~kg} / \mathrm{m}^{3}, 33.0 \mathrm{~kg} / \mathrm{m}^{3}$ and $66.3 \mathrm{~kg} / \mathrm{m}^{3}$ respectively. In this case, the nozzle is $k 0$.

detected sprays from a given test. Examples of the binary images can be found in the work of Payri et al. [52]. This calculation is done past $0.8 \mathrm{~ms}$ after SOI to guarantee that the spray is in steady state. Therefore, a black pixel corresponds to non-fluctuating regions: the spray never occupies that pixel or the pixel is always considered to be within the spray during the time window considered. On the other hand, the brighter the pixel the more likely it is for fluctuations to occur at that region (and/or the stronger fluctuations at that region are) and, as expected, this happens near the spray boundary. 


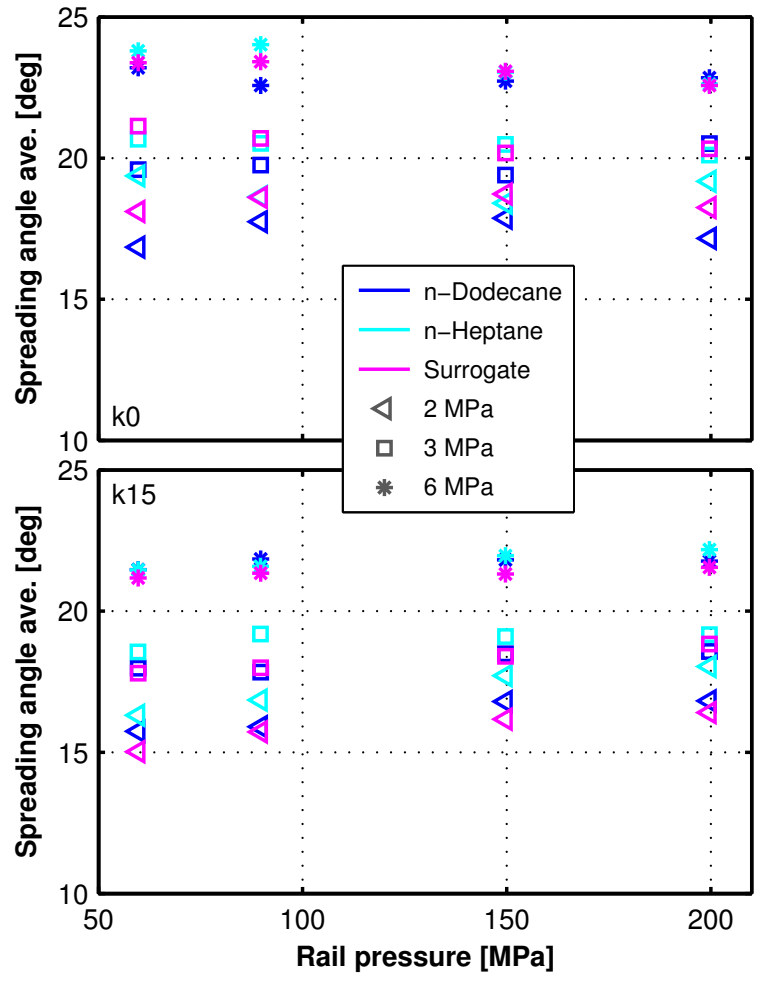

Figure 16: Time-averaged penetration-scaled spray spreading angles for all test conditions, nozzles and fuels. Note that the top part shows nozzle $k 0$ while nozzle $k 15$ is presented at the bottom part. The values reported are calculated by averaging the raw data from all test repetitions from $0.8 \mathrm{~ms}$ after SOI to the end of the signals.

Figure 17 shows quite a lot of information. First are the different shapes of the sprays produced by each nozzle. The cylindrical nozzle $k 0$ (Figure 17-left column) produces a spray that spreads quickly after the fuel has just exited the nozzle, while the spray produced by the conical nozzle $k 15$ (Figure 17-right column) spreads progressively but at a lower rate along the longitudinal coordinate. This is directly related to the higher turbulence levels and radial velocity profiles within the nozzle, caused by the cylindrical nozzle geometry, as Koo et al. [9] demonstrate in their fundamental study. This is also what the near field spreading angles presented in Figures 12 and 13 quantify. In terms of spray width, nozzle $k 0$ produces a spray that is, on average, wider up to approximately $15 \mathrm{~mm}$ from the nozzle tip, point after which both sprays start to converge to similar widths. The spray width profile along the 

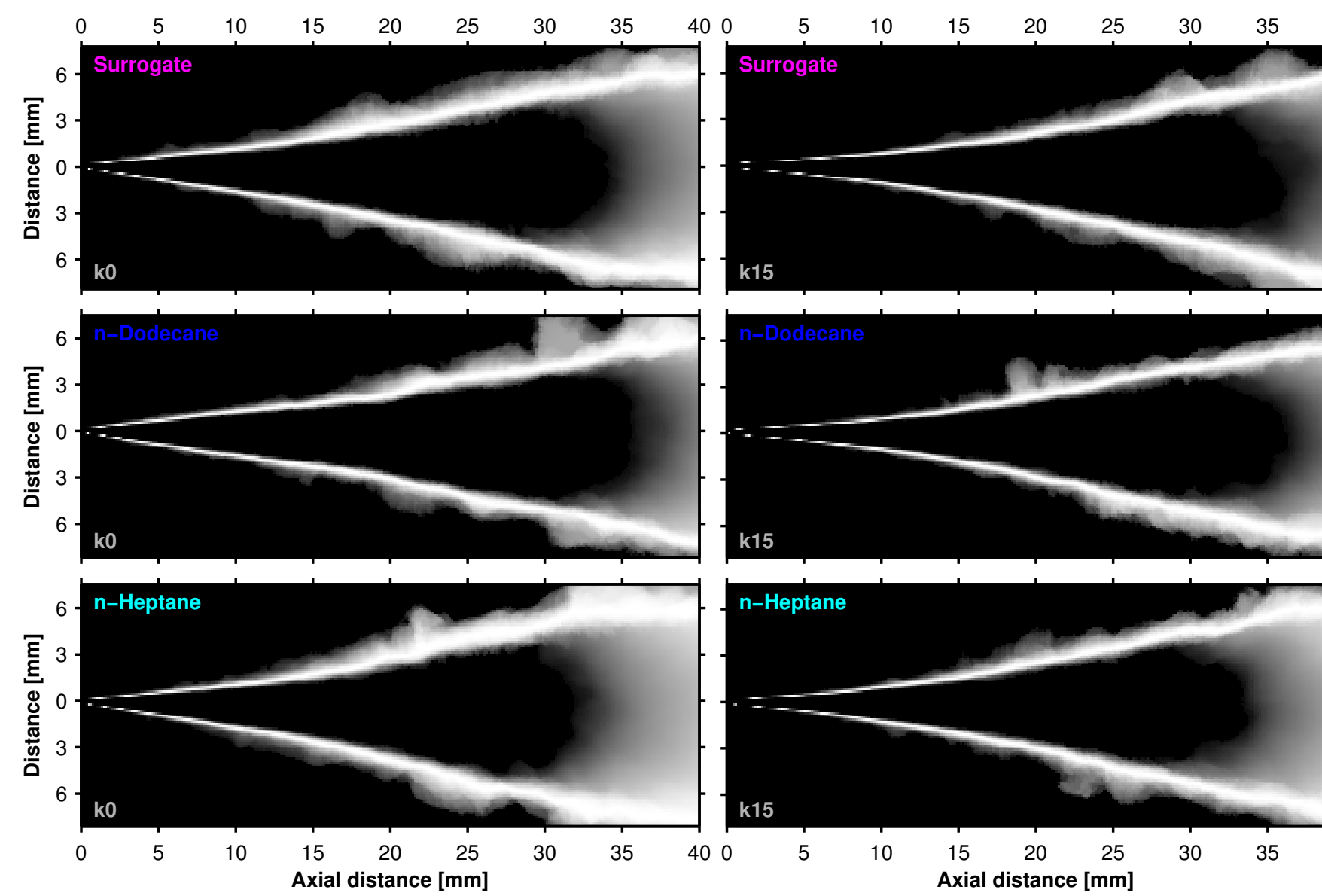

Figure 17: Spray fluctuation maps for all nozzles and fuels at a rail pressure of $60.0 \mathrm{MPa}$ and a back pressure of $2.0 \mathrm{MPa}$. The maps comprise all test repetitions and images from $0.8 \mathrm{~ms}$ after SOI to the end of the signals.

axial direction for cavitating nozzles was discussed by Payri et al. [62], while the shape of sprays that spread progressively has recently been analyzed by Pickett et al. [51] (note that in this study, the nozzle features a K-Fator of 1.5). These studies, along with the results presented here, provide evidence to the fact that nozzle geometry indeed plays a key role not only in the near field spray formation but also in the macroscopic spray. The nozzle geometry influences the behavior of the steady spray in the first millimeters which, in turn, affects the strength of the aerodynamic interactions and momentum exchange downstream. 
Moreover, the fluctuation maps presented in Figure 17 also give insight to the spray boundary fluctuations, which are also functions of turbulence, velocity profiles within the nozzle [9], and the aerodynamic interaction between the fuel spray and the ambient gas. It is important to note that, even though spreading angle fluctuations (Figure 13-bottom) may, at first, seem to be a similar metric to what the fluctuation maps show, they are somewhat independent: it is possible to have a spray with a very diffuse fluctuation map and, at the same time, a spreading angle with negligible standard deviation-i.e., the contour fluctuating over parallels. In average, up to $15 \mathrm{~mm}$ from the nozzle tip, the cylindrical nozzle $k 0$ seems to produce a more diffuse fluctuation map in comparison to the conical nozzle $k 15$, which means that its line-ofsight liquid phase spray boundary fluctuates more. Downstream, where the aerodynamic interactions have had time to shape the sprays, the fluctuations are larger and the difference between nozzles, in terms of boundary fluctuations, is reduced. The information given by these maps may imply that the differences in spray tip penetration observed in the later part of the penetration curve (and also observed by Som et al. [4], Montanaro et al. [6]) are originated in the near-nozzle region part of the steady spray - where the spray produced by the cylindrical nozzle exchanges momentum with the ambient gas at a higher rate - but are evidenced later downstream, where the differences in the remaining spray momentum is appreciable.

Figure 17 also confirms what has already been discussed: in average throughout the test matrix and for both nozzles, sprays produced by nheptane feature larger dispersion (both angle and fluctuations) when compared to those of n-dodecane and the Surrogate fuel [66, 67]. Also, the dispersion of the n-dodecane spray is less affected by the nozzle geometry in comparison to the Surrogate spray, and this result is in agreement with the spray tip penetration results presented in Figures 14 and 15 and penetrationscaled spreading angles presented in Figure 16.

\section{Conclusions}

A complete hydraulic characterization consisting of instantaneous injection rate and spray momentum flux measurements, followed by a high-speed visualization of isothermal liquid spray was carried out in combination with cylindrical and conical nozzle configurations. Two of the fuels are pure components - n-heptane and n-dodecane - while the third fuel consists of a 
three-component Surrogate to better represent the physical and chemical properties of diesel fuel.

The cylindrical nozzle, $k 0$, in spite of higher momentum flux and mass flow rate due to higher flow area, shows slower spray tip penetration and higher spread angle when compared to the conical nozzle $k 15$. This is mainly due to highly turbulent nozzle exit conditions caused by cavitation inside the cylindrical nozzle that leads to higher aerodynamic drag on the spray. At higher rail pressure and relatively low ambient/back pressure, where the aerodynamic drag is less dominant, the cylindrical nozzle spray penetration is very close to that of the conical nozzle spray. The spreading angle is found to be inversely proportional to the tip penetration. The spreading angle is dominated by the nozzle geometry followed by the ambient density. The rail pressure on the other hand, was not found to significantly influence the near-field spreading angle and has no influence on the standard deviation of the spreading angle This suggests that, even though outlet velocities increase with rail pressure - and thus, the Reynolds number - it seems not to end up playing a key role in the spray angle magnitude and fluctuations.

n-Heptane shows slowest tip penetration due to its lower density, viscosity and surface tension, all which enhance liquid breakup and momentum exchange between fuel and ambient gas. n-Dodecane and the Surrogate fuel show very similar spray behavior for variations in injection pressure and back pressure. However, the surrogate fuel shows higher penetration than ndodecane using the conical nozzle $k 15$ and lower penetration using cylindrical nozzle $k 0$, which was found to be in agreement with the near-field spreading angle and spreading angle fluctuations reported.

The experimental findings from this work on the macroscopic spray behavior, and the large database obtained (available for download at: http: //www. cmt . upv . es/DD01. aspx), could be used to validate CFD models that could help the community understand the fundamental driving mechanisms behind these observations.

\section{Acknowledgments}

This work was sponsored by Ministerio de Economía y Competitividad of the Spanish Government in the frame of the Project "Estudio de la interaccin chorro-pared en condiciones realistas de motor", Reference TRA2015-67679c2-1-R. Additionally, the employed nozzles and diesel surrogate were provided and defined by GM R\&D. 
The authors would like to thank José Enrique Del Rey, Adele Antiste and María del Carmen Tomás for their collaboration in the setup of the experiments and laboratory work, and Guillermo Miró for his help measuring fuel properties.

\section{References}

[1] J. M. Desantes, J. M. García-Oliver, J. M. Pastor, J. G. RamírezHernández, Influence of nozzle geometry on ignition and combustion for high-speed direct injection diesel engines under cold start conditions, Fuel 90 (11) (2011) 3359 - 3368, ISSN 0016-2361, doi: bibinfo $\{$ doi $\}\{10$. 1016/j.fuel.2011.06.006\}.

[2] M. R. Herfatmanesh, P. Lu, M. A. Attar, H. Zhao, Experimental investigation into the effects of two-stage injection on fuel injection quantity, combustion and emissions in a high-speed optical common rail diesel engine, Fuel 109 (2013) 1-11, ISSN 00162361, doi: \bibinfo\{doi\}\{10.1016/ j.fuel.2013.01.013\}.

[3] W. Ning, R. D. Reitz, R. Diwakar, A. M. Lippert, A Numerical Investigation of Nozzle Geometry and Injection Condition Effects on Diesel Fuel Injector Flow Physics, SAE Technical Paper 2008-01-0936, doi: \bibinfo\{doi $\}\{10.4271 / 2008-01-0936\}$.

[4] S. Som, A. I. Ramirez, D. E. Longman, S. K. Aggarwal, Effect of nozzle orifice geometry on spray, combustion, and emission characteristics under diesel engine conditions, Fuel 90 (3) (2011) 1267 - 1276, ISSN 00162361, doi:\bibinfo\{doi\}\{http://dx.doi.org/10.1016/j.fuel.2010.10.048\}.

[5] M. Battistoni, C. Grimaldi, F. Mariani, Coupled simulation of nozzle flow and spray formation using diesel and biodiesel for CI engine applications, SAE Technical Paper 2012-01-1267, doi: \bibinfo $\{$ doi $\}\{10.4271 /$ 2012-01-1267\}.

[6] A. Montanaro, M. Migliacco, L. Allocca, V. Friaoli, S.-Y. Lee, A. Zhang, J. Naber, Schlieren and mie scattering visualization for single hole diesel injector under vaporizing conditions with numerical validation, SAE Technical Paper 2014-01-1406, doi: \bibinfo\{doi\}\{10.4271/ 2014-01-1406\}. 
[7] C. Badock, R. Wirth, C. Tropea, The influence of hydro grinding on cavitation inside a diesel injection nozzle and primary break-up under unsteady pressure conditions, Proc. 15th ILASS-Europe 99 (1999) 5-7.

[8] L. C. Ganippa, S. Andersson, J. Chomiak, A. Matsson, Combustion characteristics of diesel sprays from equivalent nozzles with sharp and rounded inlet geometries, Combustion Science and Technology 175 (6) (2003) 1015-1032, doi: \bibinfo\{doi $\{10.1080 / 00102200302350\}$.

[9] J. Y. Koo, S. T. Hong, J. S. Shakal, S. Goto, Influence of Fuel Injector Nozzle Geometry on Internal and External Flow Characteristics, SAE Technical Paper 970354, doi: \bibinfo\{doi $\}\{10.4271 / 970354\}$.

[10] J.-S. Han, P.-H. Lu, X.-B. Xie, M.-C. Lai, N. A. Henein, Investigation of Diesel Spray Primary Break-up and Development for Different Nozzle Geometries, SAE Technical Paper 2002-01-2775, doi: \bibinfo\{doi $\}\{10$. 4271/2002-01-2775\}.

[11] M. Blessing, G. Knig, C. Krger, U. Michels, V. Schwarz, Analysis of Flow and Cavitation Phenomena in Diesel Injection Nozzles and Its Effects on Spray and Mixture Formation, SAE Technical Paper 2003-01-1358, doi: \bibinfo $\{$ doi $\}\{10.4271 / 2003-01-1358\}$.

[12] H. K. Suh, C. S. Lee, Effect of cavitation in nozzle orifice on the diesel fuel atomization characteristics, International Journal of Heat and Fluid Flow 29 (4) (2008) 1001 - 1009, ISSN 0142-727X, doi: \bibinfo\{doi $\}\{10$. 1016/j.ijheatfluidflow.2008.03.014\}.

[13] S. Som, A. I. Ramirez, S. K. Aggarwal, A. L. Kastengren, E. M. ElHannouny, D. E. Longman, C. F. Powell, P. K. Senecal, Development and Validation of a Primary Breakup Model for Diesel Engine Applications, SAE Technical Paper 2009-01-0838, doi: \bibinfo $\{$ doi $\}\{10.4271 /$ 2009-01-0838\}.

[14] S. Som, S. K. Aggarwal, Modeling diesel spray flame lift-off using detailed chemistry and a new primary breakup model, in: 47th AIAA Aerospace sciences meeting including the new horizons forum and aerospace exposition, Orlando, Florida, 5 - 8 January, doi: $\backslash$ bibinfo $\{$ doi $\}$ $\{10.2514 / 6.2009-666\}, 2009$. 
[15] S. Som, S. K. Aggarwal, Effects of primary breakup modeling on spray and combustion characteristics of compression ignition engines, Combustion and Flame 157 (6) (2010) 1179 - 1193, ISSN 0010-2180, doi: \bibinfo\{doi\}\{10.1016/j.combustflame.2010.02.018\}.

[16] Z. Liu, K.-S. Im, Y. Wang, K. Fezzaa, X.-B. Xie, M.-C. Lai, J. Wang, Near-Nozzle Structure of Diesel Sprays Affected by Internal Geometry of Injector Nozzle: Visualized by Single-Shot X-ray Imaging, SAE Technical Paper 2010-01-0877, doi: \bibinfo\{doi $\}\{10.4271 / 2010-01-0877\}$.

[17] R. Morgan, J. Wray, D. A. Kennaird, C. Crua, M. R. Heikal, The Influence of Injector Parameters on the Formation and Break-Up of a Diesel Spray, SAE Technical Paper doi: $\backslash$ bibinfo $\{$ doi $\}\{10.4271 / 2001-01-0529\}$.

[18] F. Payri, V. Bermúdez, R. Payri, F. J. Salvador, The influence of cavitation on the internal flow and the spray characteristics in diesel injection nozzles, Fuel 83 (4-5) (2004) 419 - 431, ISSN 0016-2361, doi: $\backslash$ bibinfo\{doi $\{10.1016 /$ j.fuel.2003.09.010 $\}$.

[19] R. Payri, F. J. Salvador, J. Gimeno, L. D. Zapata, Diesel nozzle geometry influence on spray liquid-phase fuel penetration in evaporative conditions, Fuel 87 (7) (2008) 1165 - 1176, ISSN 0016-2361, doi: $\backslash$ bibinfo\{doi $\}\{10.1016 /$ j.fuel.2007.05.058\}.

[20] A. Zhang, A. Montanaro, L. Allocca, J. Naber, S.-Y. Lee, Measurement of Diesel Spray Formation and Combustion upon Different Nozzle Geometry using Hybrid Imaging Technique, SAE Technical Paper 201401-1410 doi:〈bibinfo $\{$ doi $\}\{10.4271 / 2014-01-1410\}$.

[21] J. M. Desantes, R. Payri, J. Gimeno, P. Martí-Aldaraví, Simulation of the First Millimeters of the Diesel Spray by an Eulerian Spray Atomization Model Applied on ECN Spray A Injector, SAE Technical Paper 2014-01-1418, doi: $\backslash$ bibinfo $\{$ doi $\}\{10.4271 / 2014-01-1418\}$.

[22] M. Battistoni, Q. Xue, S. Som, E. Pomraning, Effect of Off-Axis Needle Motion on Internal Nozzle and Near Exit Flow in a Multi-Hole Diesel Injector, SAE Int. J. Fuels Lubr. 7 (2014) 167-182, doi:\bibinfo\{doi\} $\{10.4271 / 2014-01-1426\}$.

[23] F. J. Salvador, J. Gimeno, J. M. Pastor, P. Martí-Aldaraví, Effect of turbulence model and inlet boundary condition on the Diesel 
spray behavior simulated by an Eulerian Spray Atomization (ESA) model, International Journal of Multiphase Flow 65 (0) (2014) 108 - 116, ISSN 0301-9322, doi:〈bibinfo\{doi\}\{http://dx.doi.org/10.1016/j. ijmultiphaseflow.2014.06.003\}.

[24] Q. Xue, M. Battistoni, S. Som, S. Quan, P. K. Senecal, E. Pomraning, D. Schmidt, Eulerian CFD Modeling of Coupled Nozzle Flow and Spray with Validation Against X-Ray Radiography Data, SAE Int. J. Engines 7 (2014) 1061-1072, doi:〈bibinfo\{doi $\}\{10.4271 / 2014-01-1425\}$.

[25] Q. Xue, M. Battistoni, C. F. Powell, D. E. Longman, S. P. Quan, E. Pomraning, P. K. Senecal, D. P. Schmidt, S. Som, An Eulerian CFD model and X-ray radiography for coupled nozzle flow and spray in internal combustion engines, International Journal of Multiphase Flow 70 (2015) 77 - 88, ISSN 0301-9322, doi: bibinfo\{doi\}\{http://dx.doi.org/ 10.1016/j.ijmultiphaseflow.2014.11.012\}.

[26] J. M. Desantes, J. M. García-Oliver, J. M. Pastor, A. Pandal, E. Baldwin, D. P. Schmidt, Coupled/decoupled spray simulation comparison of the ECN spray a condition with the $\Sigma$-Y Eulerian atomization model, International Journal of Multiphase Flow 80 (2016) 89-99, ISSN 03019322, doi: \bibinfo\{doi\}\{10.1016/j.ijmultiphaseflow.2015.12.002\}.

[27] M. Bardi, R. Payri, L. M. Malbec, G. Bruneaux, L. M. Pickett, J. Manin, T. Bazyn, C. Genzale, Engine Combustion Network: comparison of spray development, vaporization, and combustion in different combustion vessels, Atomization and Sprays 22 (10) (2012) 807 - 842, doi: $\backslash$ bibinfo\{doi $\}\{10.1615 /$ AtomizSpr.2013005837\}.

[28] H. Curran, P. Gaffuri, W. Pitz, C. Westbrook, A Comprehensive Modeling Study of n-Heptane Oxidation, Combustion and Flame 114 (12) (1998) 149 - 177, ISSN 0010-2180, doi:\bibinfo $\{$ doi $\}\{10.1016 /$ S0010-2180(97)00282-4\}.

[29] J. T. Farrell, N. P. Cernansky, F. L. Dryer, C. K. Law, D. G. Friend, C. A. Hergart, R. M. McDavid, A. K. Patel, C. J. Mueller, H. Pitsch, Development of an Experimental Database and Kinetic Models for Surrogate Diesel Fuels, SAE Technical Paper 2007-01-0201, doi: \bibinfo\{doi\}\{10.4271/2007-01-0201\}. 
[30] F. Battin-Leclerc, Detailed chemical kinetic models for the lowtemperature combustion of hydrocarbons with application to gasoline and diesel fuel surrogates, Progress in Energy and Combustion Science 34 (4) (2008) 440 - 498, ISSN 0360-1285, doi: \bibinfo $\{$ doi $\}\{10.1016 / j$. pecs.2007.10.002\}.

[31] M. Raju, M. Wang, P. Senecal, S. Som, D. E. Longman, A Reduced Diesel Surrogate Mechanism for Compression Ignition Engine Applications, in: ASME 2012 Internal Combustion Engine Division Fall Technical Conference, American Society of Mechanical Engineers, 711-722, 2012 .

[32] R. H. Natelson, M. S. Kurman, N. P. Cernansky, D. L. Miller, Experimental investigation of surrogates for jet and diesel fuels, Fuel 87 (1011) (2008) 2339 - 2342, ISSN 0016-2361, doi: \bibinfo\{doi\}\{10.1016/j.fuel. 2007.11.009\}.

[33] W. J. Pitz, C. J. Mueller, Recent progress in the development of diesel surrogate fuels, Progress in Energy and Combustion Science 37 (3) (2011) 330 - 350, ISSN 0360-1285, doi: \bibinfo\{doi $\}\{10.1016 / j . p e c s$. 2010.06.004\}.

[34] H. Pitsch, H. Barths, N. Peters, Three-Dimensional Modeling of NOx and Soot Formation in DI-Diesel Engines Using Detailed Chemistry Based on the Interactive Flamelet Approach, SAE Technical Paper 962057, doi: \bibinfo\{doi $\}\{10.4271 / 962057\}$.

[35] J. Luo, M. Yao, H. Liu, B. Yang, Experimental and numerical study on suitable diesel fuel surrogates in low temperature combustion conditions, Fuel 97 (0) (2012) 621 - 629, ISSN 0016-2361, doi: bibinfo $\{$ doi $\}\{10$. 1016/j.fuel.2012.02.057\}.

[36] C. A. Idicheria, L. M. Pickett, Soot Formation in Diesel Combustion under High-EGR Conditions, SAE 2005-01-3834, doi: \bibinfo $\{$ doi $\}\{10$. 4271/2005-01-3834\}.

[37] S. Som, S. K. Aggarwal, E. M. El-Hannouny, D. E. Longman, Investigation of nozzle flow and cavitation characteristics in a diesel injector, Journal of Engineering for Gas Turbines and Power 132 (4) (2010) 042802, doi: \bibinfo\{doi\}\{10.1115/1.3203146\}. 
[38] P.-C. Chen, W.-C. Wang, W. L. Roberts, T. Fang, Spray and atomization of diesel fuel and its alternatives from a single-hole injector using a common rail fuel injection system, Fuel 103 (0) (2013) 850 - 861, ISSN 0016-2361, doi:〈bibinfo\{doi\}\{10.1016/j.fuel.2012.08.013\}.

[39] R. Payri, F. J. Salvador, J. Gimeno, O. Venegas, Study of cavitation phenomenon using different fuels in a transparent nozzle by hydraulic characterization and visualization, Experimental Thermal and Fluid Science 44 (2013) 235 - 244, ISSN 0894-1777, doi: \bibinfo\{doi\}\{10.1016/j. expthermflusci.2012.06.013\}.

[40] R. Payri, J. M. García-Oliver, M. Bardi, J. Manin, Fuel temperature influence on diesel sprays in inert and reacting conditions, Applied Thermal Engineering 35 (March) (2012) 185-195, ISSN 13594311, doi: $\backslash$ bibinfo\{doi\}\{10.1016/j.applthermaleng.2011.10.027\}.

[41] E. W. Lemmon, M. O. McLinden, D. G. Friend, Thermophysical Properties of Fluid Systems, in: P. J. Linstrom, W. G. Mallard (Eds.), NIST Chemistry WebBook, NIST Standard Reference Database Number 69, URL http://webbook.nist.gov, 2011.

[42] R. Payri, F. J. Salvador, J. Gimeno, G. Bracho, A new methodology for correcting the signal cumulative phenomenon on injection rate measurements, Experimental Techniques 32 (1) (2008) 46-49, ISSN 1747-1567, doi:〈bibinfo\{doi\}\{10.1111/j.1747-1567.2007.00188.x .

[43] R. Payri, J. M. García, F. J. Salvador, J. Gimeno, Using spray momentum flux measurements to understand the influence of diesel nozzle geometry on spray characteristics, Fuel 84 (5) (2005) 551-561, doi: $\backslash$ bibinfo\{doi $\}\{10.1016 /$ j.fuel.2004.10.009\}.

[44] J. D. Naber, D. L. Siebers, Effects of Gas Density and Vaporization on Penetration and Dispersion of Diesel Sprays, SAE Technical Paper 960034, doi: bibinfo $\{$ doi $\}\{10.4271 / 960034\}$.

[45] L. M. Pickett, J. Manin, C. L. Genzale, D. L. Siebers, M. P. B. Musculus, C. A. Idicheria, Relationship Between Diesel Fuel Spray Vapor Penetration/Dispersion and Local Fuel Mixture Fraction, SAE Int. J. Engines 4 (2011) 764-799, doi: bibinfo\{doi $\}\{10.4271 / 2011-01-0686\}$. 
[46] R. Payri, S. Molina, F. J. Salvador, J. Gimeno, A study of the relation between nozzle geometry, internal flow and sprays characteristics in diesel fuel injection systems, KSME International Journal 18 (7) (2004) 1222-1235, ISSN 1738-494X, doi:〈bibinfo\{doi\}\{10.1007/BF02983297\}.

[47] J. M. Desantes, R. Payri, F. J. Salvador, V. Soare, Study of the Influence of Geometrical and Injection Parameters on Diesel Sprays Characteristics in Isothermal Conditions, SAE Technical Paper 2005-01-0913, doi: bibinfo $\{$ doi $\}\{10.4271 / 2005-01-0913\}$.

[48] J. M. Desantes, R. Payri, F. J. Salvador, A. Gil, Development and validation of a theoretical model for diesel spray penetration, Fuel 85 (78) (2006) 910 - 917, ISSN 0016-2361, doi: bibinfo\{doi\}\{10.1016/j.fuel. 2005.10.023\}.

[49] L. M. Pickett, C. L. Genzale, J. Manin, L. Malbec, L. Hermant, Measurement uncertainty of liquid penetration in evaporating diesel sprays, ILASS2011-111 .

[50] J. Manin, M. Bardi, L. Pickett, Evaluation of the liquid length via diffused back-illumination imaging in vaporizing diesel sprays, in: The eighth international conference for modeling and diagnostics for advanced engine systems (COMODIA 2012), 2012.

[51] L. M. Pickett, J. Manin, R. Payri, M. Bardi, J. Gimeno, Transient Rate of Injection Effects on Spray Development, SAE Technical Paper 201324-0001, doi: \bibinfo $\{$ doi $\}\{10.4271 / 2013-24-0001\}$.

[52] R. Payri, J. Gimeno, J. P. Viera, A. H. Plazas, Needle lift profile influence on the vapor phase penetration for a prototype diesel direct acting piezoelectric injector, Fuel 113 (0) (2013) 257 - 265, ISSN 0016-2361, doi:〈bibinfo\{doi\}\{http://dx.doi.org/10.1016/j.fuel.2013.05.057\}.

[53] J. M. Desantes, R. Payri, F. J. Salvador, J. De la Morena, Influence of cavitation phenomenon on primary break-up and spray behavior at stationary conditions, Fuel 89 (10) (2010) 3033 - 3041, ISSN 0016-2361, doi:〈bibinfo\{doi\}\{http://dx.doi.org/10.1016/j.fuel.2010.06.004\}.

[54] T. Qiu, X. Song, Y. Lei, H. Dai, C. Cao, H. Xu, X. Feng, Effect of back pressure on nozzle inner flow in fuel injector, Fuel 173 (2016) 79-89, ISSN 00162361, doi:\bibinfo\{doi\}\{10.1016/j.fuel.2016.01.044\}. 
[55] Z. He, G. Guo, X. Tao, W. Zhong, X. Leng, Q. Wang, Study of the effect of nozzle hole shape on internal flow and spray characteristics, International Communications in Heat and Mass Transfer 71 (2016) 18, ISSN 07351933, doi:〈bibinfo\{doi $\}$ 10.1016/j.icheatmasstransfer.2015. $12.002\}$.

[56] J. M. Desantes, R. Payri, A. Garcia, J. Manin, Experimental Study of Biodiesel Blends Effects on Diesel Injection Processes, Energy \& Fuels 23 (6) (2009) 3227-3235, ISSN 0887-0624, doi:〈bibinfo\{doi\}\{10.1021/ ef $801102 \mathrm{w}$.

[57] J. Dernotte, C. Hespel, F. Foucher, S. Houill, C. Mounam-Rousselle, Influence of physical fuel properties on the injection rate in a Diesel injector, Fuel 96 (2012) 153 - 160, ISSN 0016-2361, doi:〈bibinfo\{doi\} \{http://dx.doi.org/10.1016/j.fuel.2011.11.073\}.

[58] R. Payri, F. J. Salvador, M. Carreres, J. De la Morena, Fuel temperature influence on the performance of a last generation common-rail diesel ballistic injector. Part II: 1D model development, validation and analysis, Energy Conversion and Management 114 (2016) 376-391, ISSN 01968904, doi: \bibinfo $\{$ doi $\}\{10.1016 /$ j.enconman.2016.02.043\}.

[59] Z.-Y. Sun, G.-X. Li, C. Chen, Y.-S. Yu, G.-X. Gao, Numerical investigation on effects of nozzles geometric parameters on the flow and the cavitation characteristics within injectors nozzle for a high-pressure common-rail DI diesel engine, Energy Conversion and Management 89 (2015) 843-861, ISSN 01968904, doi: bibinfo\{doi\}\{10.1016/j.enconman. 2014.10.047\}.

[60] R. Payri, F. J. Salvador, J. Gimeno, R. Novella, Flow regime effects on non-cavitating injection nozzles over spray behavior, International Journal of Heat and Fluid Flow 32 (1) (2011) 273 - 284, ISSN 0142-727X, doi: \bibinfo\{doi\}\{http://dx.doi.org/10.1016/j.ijheatfluidflow.2010.10.001\}.

[61] A. Andriotis, M. Gavaises, Influence of vortex flow and cavitation on near-nozzle diesel spray dispersion angle, Atomization and Sprays 19 (3) (2009) 247-261, ISSN 1044-5110.

[62] R. Payri, F. J. Salvador, J. Gimeno, J. De la Morena, Analysis of diesel spray atomization by means of a near-nozzle field visualization technique, Atomization and Sprays 21 (9) (2011) 753-774, ISSN 1044-5110. 
[63] E. Delacourt, B. Desmet, B. Besson, Characterisation of very high pressure diesel sprays using digital imaging techniques, Fuel 84 (7-8) (2005) 859 - 867, ISSN 0016-2361, doi:〈bibinfo\{doi\}\{http://dx.doi.org/ 10.1016/j.fuel.2004.12.003\}.

[64] B. Mohan, W. Yang, K. L. Tay, W. Yu, Experimental study of spray characteristics of biodiesel derived from waste cooking oil, Energy Conversion and Management 88 (2014) 622 - 632, ISSN 0196-8904, doi: bibinfo\{doi\}\{http://dx.doi.org/10.1016/j.enconman.2014.09.013\}.

[65] B. Mohan, W. Yang, K. L. Tay, W. Yu, Macroscopic spray characterization under high ambient density conditions, Experimental Thermal and Fluid Science 59 (2014) 109 - 117, ISSN 0894-1777, doi:\bibinfo\{doi\} \{http://dx.doi.org/10.1016/j.expthermflusci.2014.08.003\}.

[66] C. Crua, M. R. Heikal, M. R. Gold, Microscopic imaging of the initial stage of diesel spray formation, Fuel 157 (2015) 140-150, ISSN 00162361, doi:〈bibinfo\{doi\}\{10.1016/j.fuel.2015.04.041\}.

[67] H. Ding, Z. Wang, Y. Li, H. Xu, C. Zuo, Initial dynamic development of fuel spray analyzed by ultra high speed imaging, Fuel 169 (2016) 99-110, ISSN 00162361, doi: \bibinfo\{doi\}\{10.1016/j.fuel.2015.11.083\}.

[68] Y. Park, J. Hwang, C. Bae, K. Kim, J. Lee, S. Pyo, Effects of diesel fuel temperature on fuel flow and spray characteristics, Fuel 162 (2015) 1-7, ISSN 00162361, doi:\bibinfo\{doi\}\{10.1016/j.fuel.2015.09.008\}. 